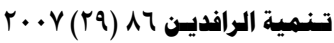 \\ ص ص [rY-q
}

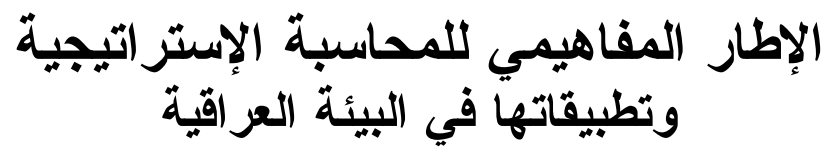

مقداد احمد يحيى الجليلي

أستاذ مساعد فنسم المحاسبة الإنية

كلية الإدارة و الاقتصاد - جامعة الموصل

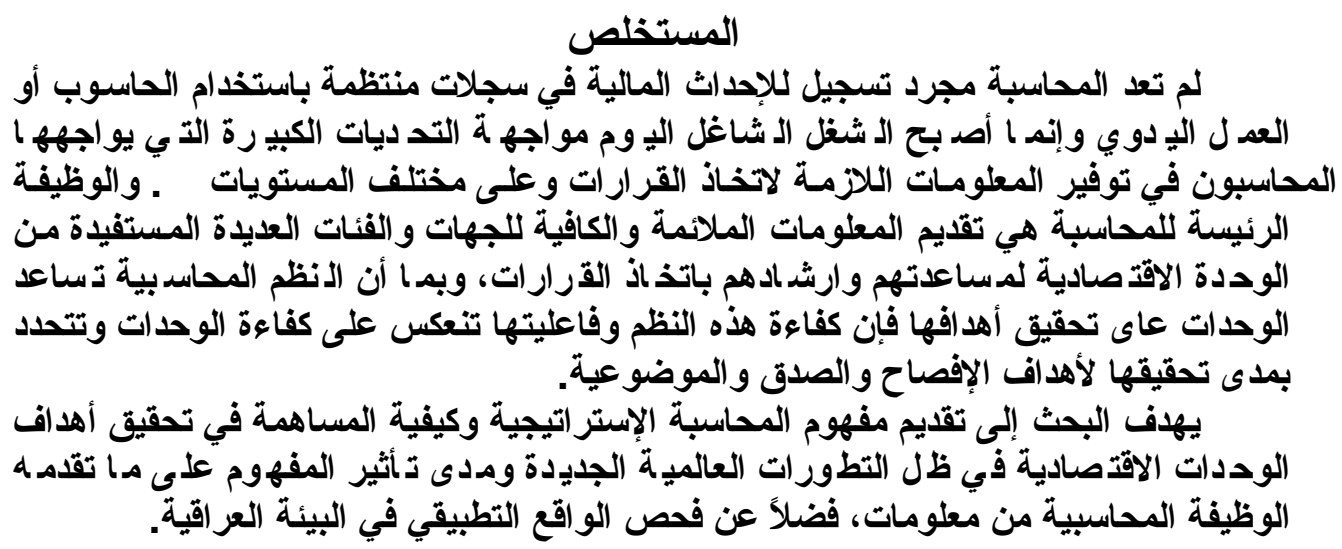

\section{The Conceptual Template of the Strategic Accountancy and The Applications in Iraqi Environment}

\author{
Moqdad A. Al - Jalili \\ Assistant professor of Accountancy \\ University of Mosul
}

\begin{abstract}
Accounting has no longer merely a record of the financial events in a regular record by using computer or manual job, but it has become nowadays able to face a big challenge in submitting the necessary and enough information for many enterprises and categories used it in the economic unit in order to help them for making decision. The accounting system may help the units in achieving their targets, so the efficiency and activity of the systems probably affect the efficiency of these units to achieve disclosure, faithfulness and objectivity.

The research aims at submitting the definition of accounting strategy and the contribution to achieve the targets in the economic unites under the new development and the effect of definition on information submitted by the accounting profession and also the testing the application in Iraqi environment.
\end{abstract}

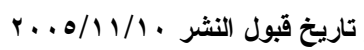




\section{(المقدمة}

شهدت الآونة الأخيرة وعلى مدار القرنين الأخيرين العديد من التطورات في

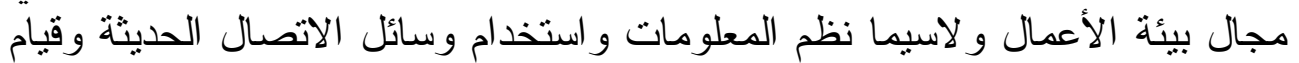

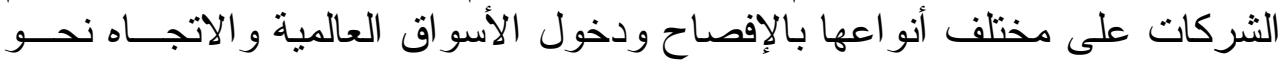

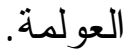

لهم تعد المحاسبة مجرد تسجيل للإحداث المالية في سجلات منتظمة باستخدام

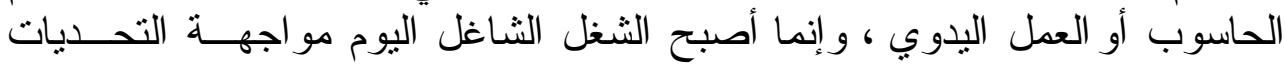

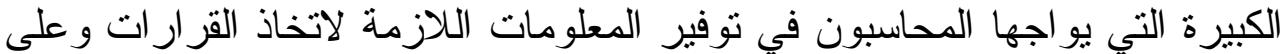

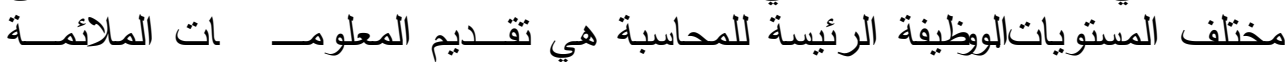

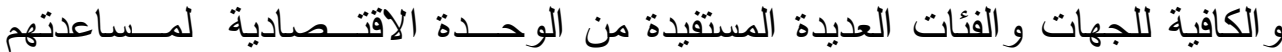

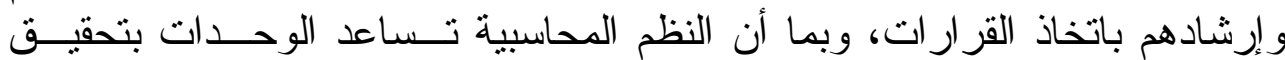

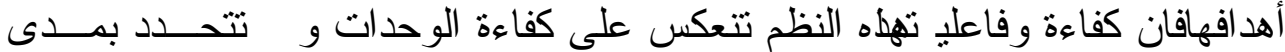

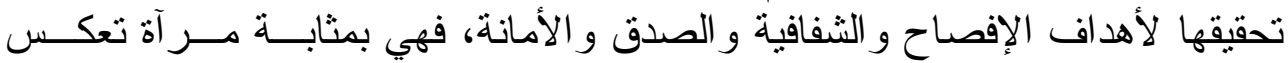

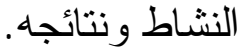

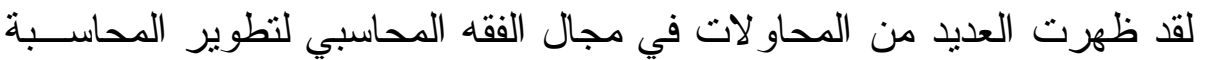

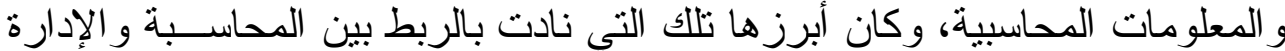

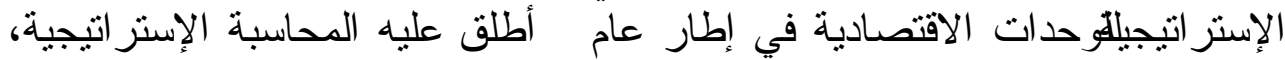

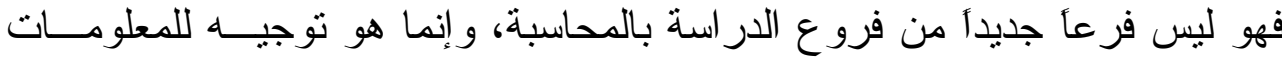
المحاسبية لتحقيق أهداف الإدارة الاستر اتيجية.

مشكلة البحث

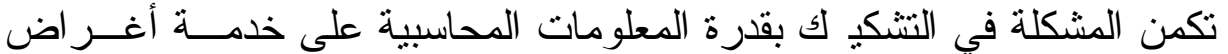

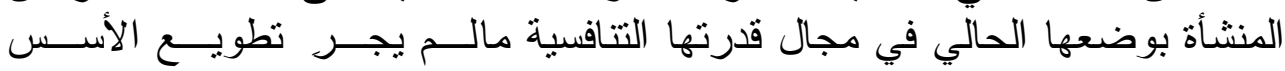

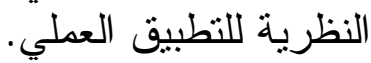

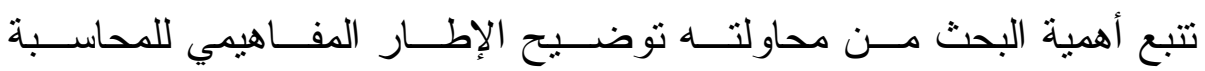
أهمية البحث

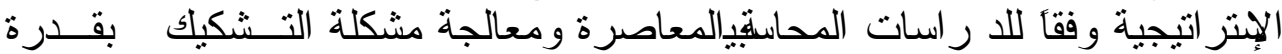

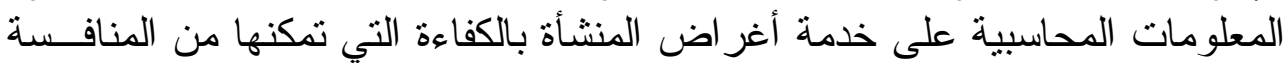

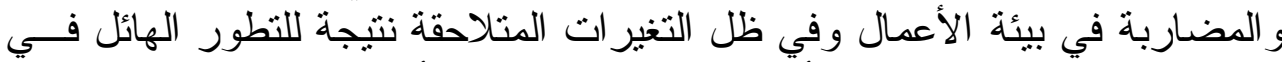

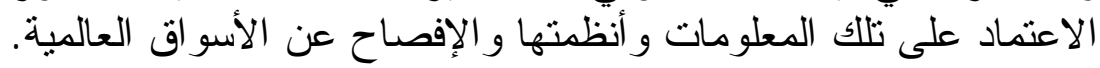

هاف البحث

يهدف البحث إلى تقديم مفهوم المحاسبة الاستر اتيجية وكيفية المسـاهمة فــي

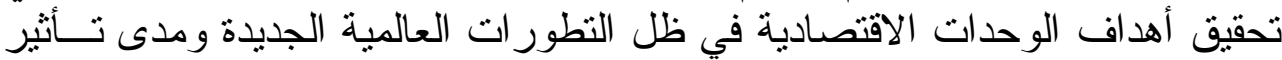

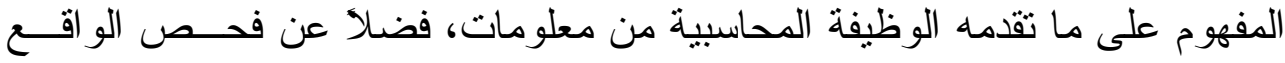


التطبيقي في البيئة العر اقية لمغرض تحقيق هدف البح ث فقد ثم تقسيمه على ثناثــة : أقسام :

الأول: التأصيل العلمي للمحاسبة الإستر اتيجية الثاني: المحاسبة الإستر اتيجية و أثزها على الإنى المعلومات الماتية المحاسبية

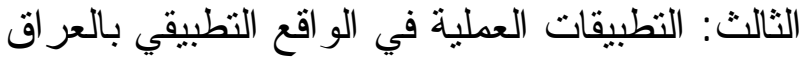

\section{أولاً - التأصيل العلمي للمحاسبة الإستر اتيجية}

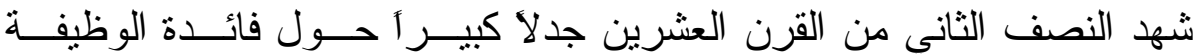

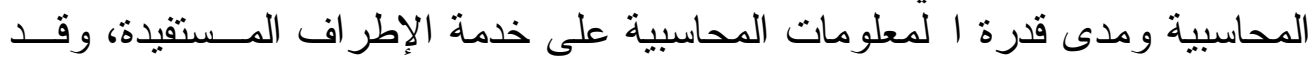

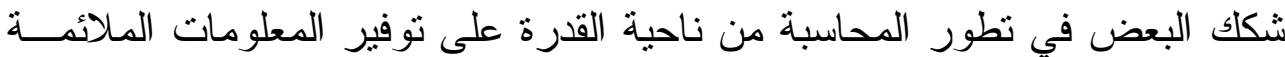

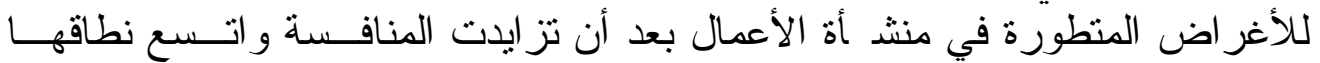

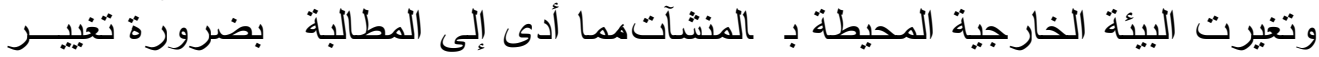
الأتي: وتيرت أ. طبيعة المعلومات التي توفر ها الوظيفة المحاسبية. ب. المهار ات التي يمتلكها المحاسبون. توفئ.

ج. الدور الذي يؤديه المحاسبون من أجل تحقيق المنشآت لأهدافها في المحافظــــة

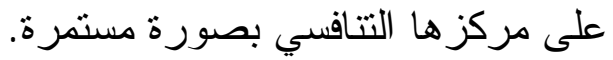

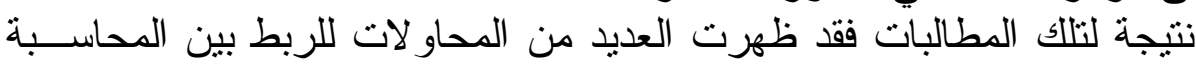
وبين الإدارة الاستر اتيجية بهدف تقديم المعلومات المفيدة لاتخاذ القرار التهات التهات الملائمة

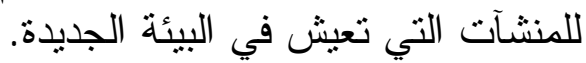

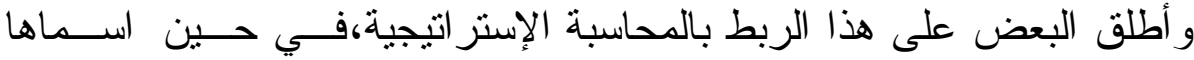

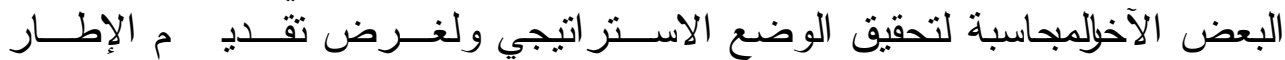

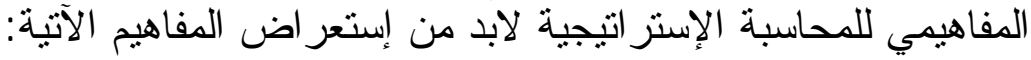

\section{ا 1 - الإدارة الإستر اتيجية}

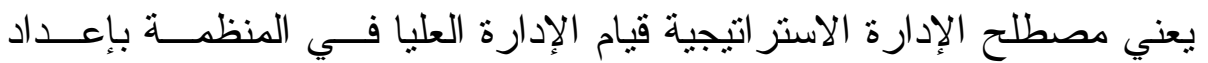

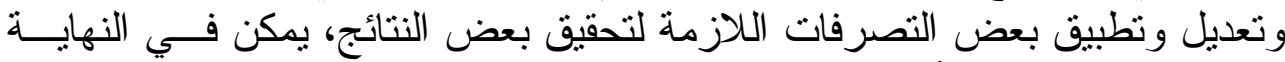

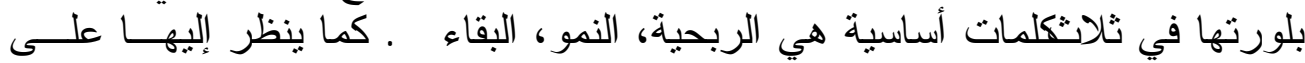

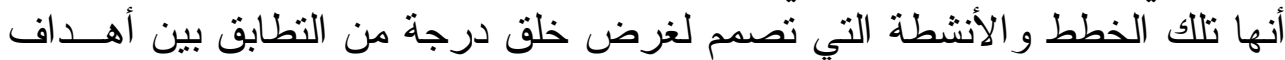

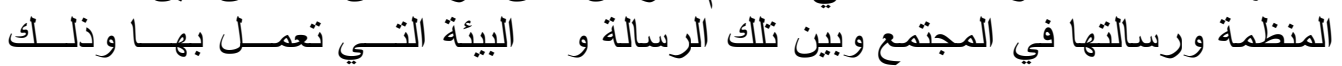

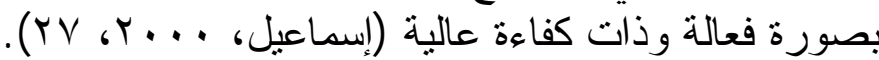

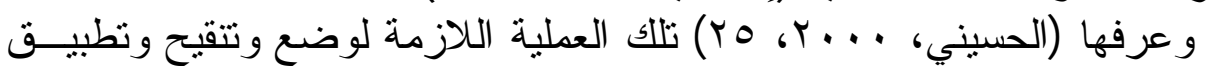

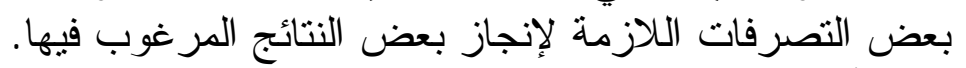

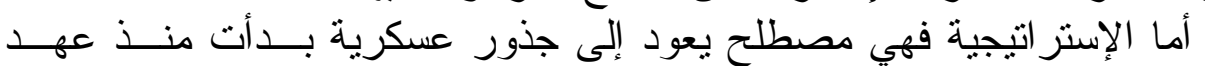

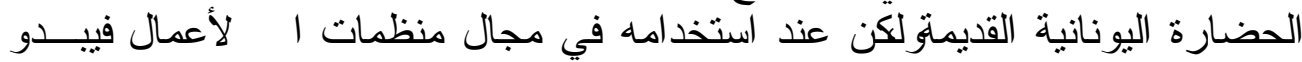

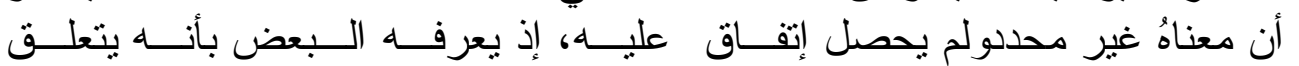


بتحقيق الإستر اتيجية (Mintzberg, 1987,11) ويرون بأن الخطط قــيرة الأجـلـ

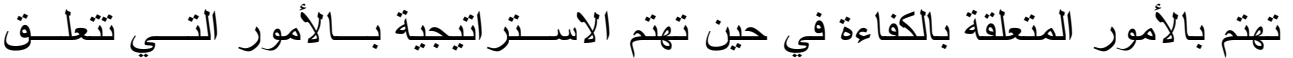

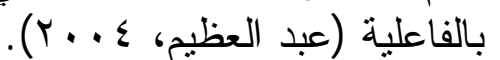

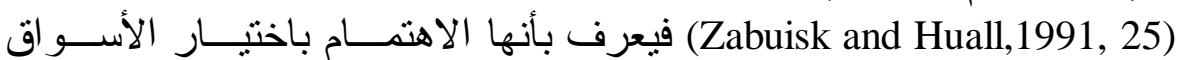

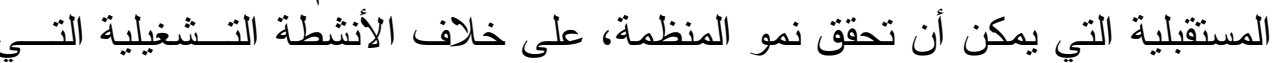

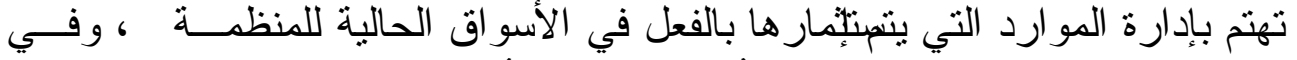

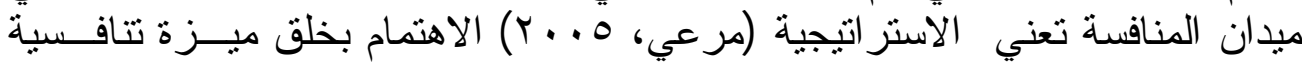

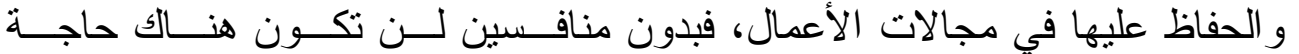

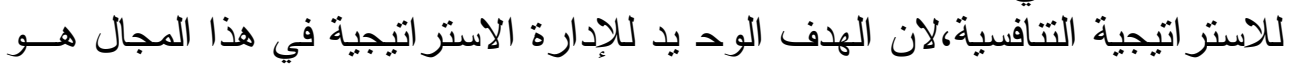
تمكين المنظمة من تحقيق ميزة مستمرة عن منافسيها.

\section{r r- l}

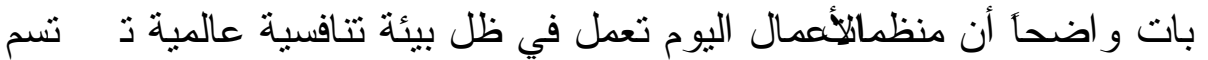

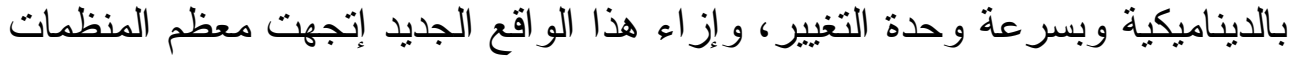

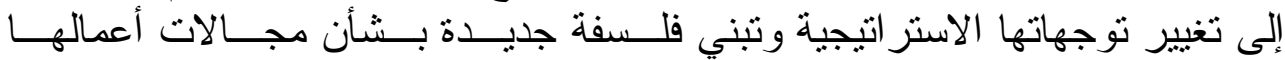

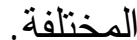

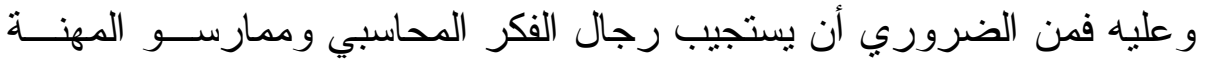

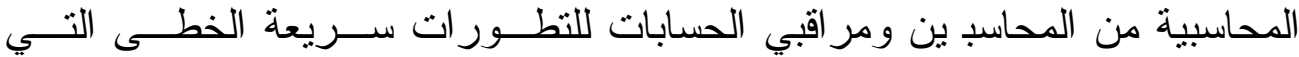

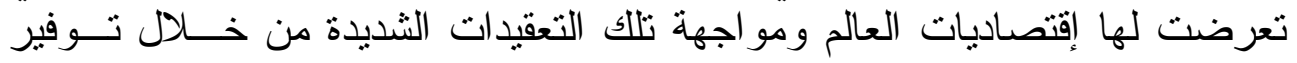

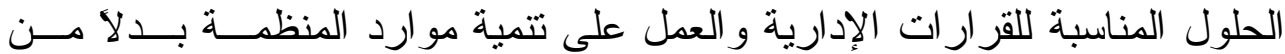

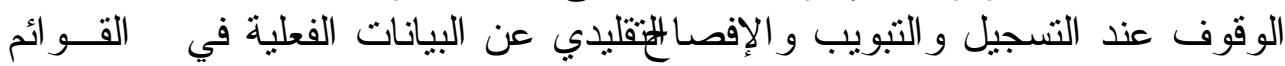

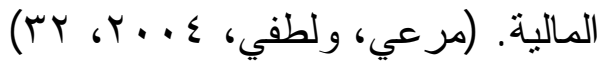

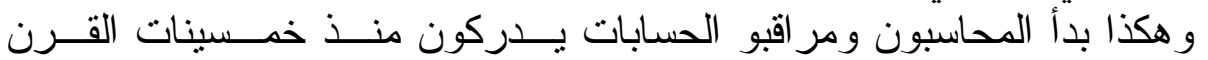

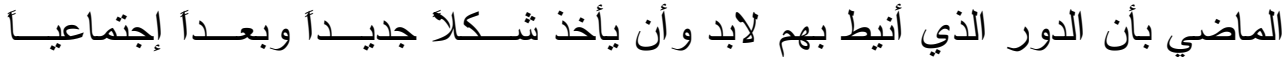

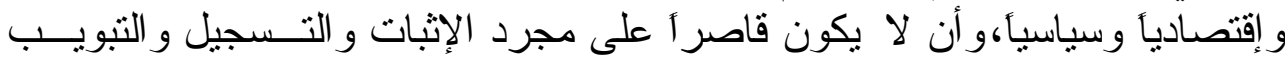

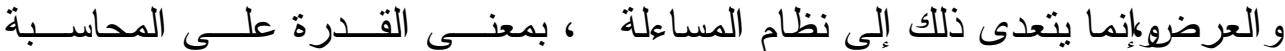

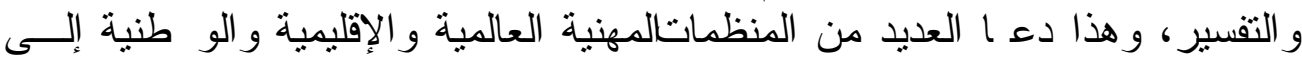

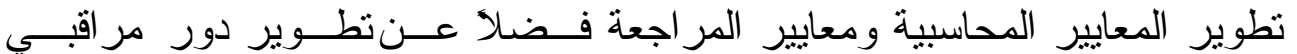

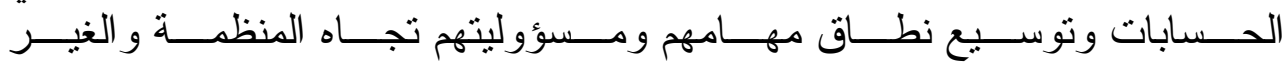
.(http://www.ardo.org.eg)

\section{1 - - ا تغير دور الوظيفة المحاسبية داخل المنظمة}

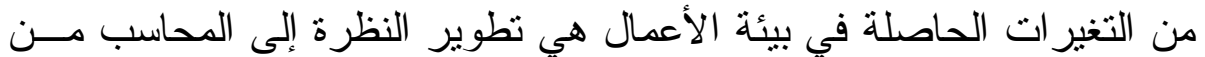

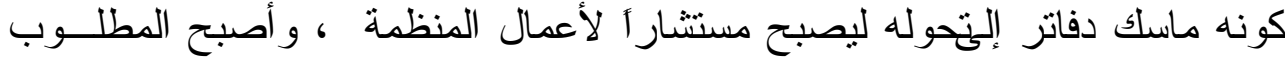

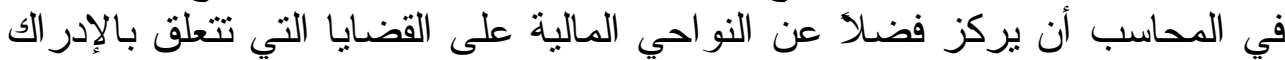
التفصيلي للمنظمة و البيئة التي تعمل فيله وأن يوحد جه وده مع عدة وظائف أخرى الخرى 


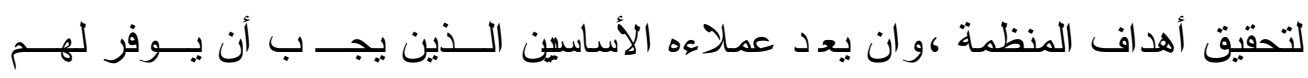

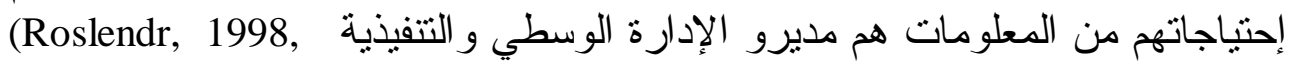

كما شملت و اجبات المحاسب صباغة الاستز اتيجيات وتطبيقها ومساعدة بــاقي

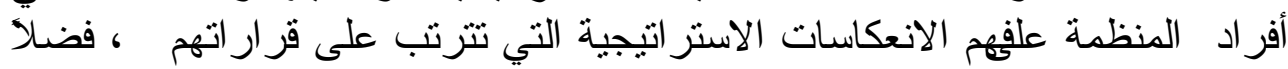

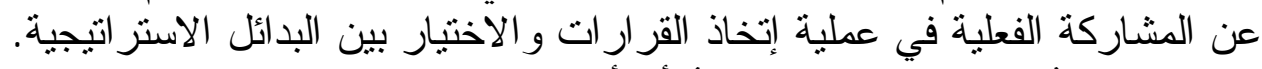

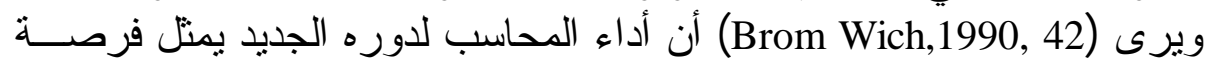

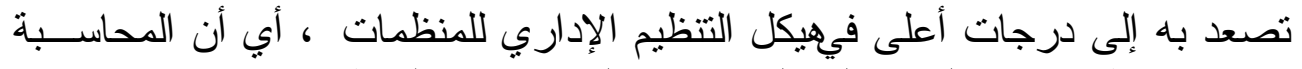

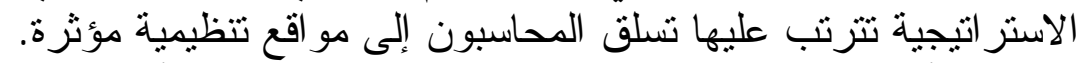

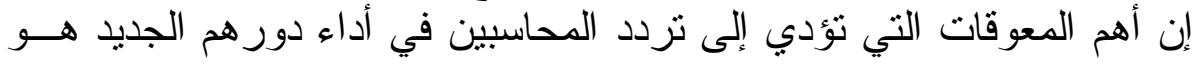

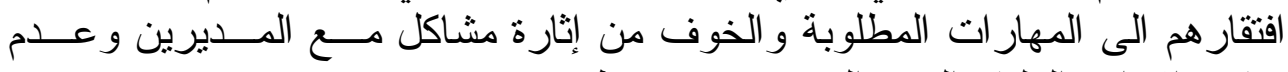

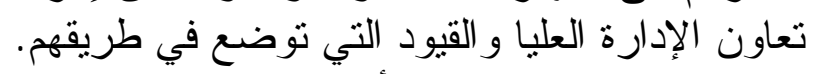

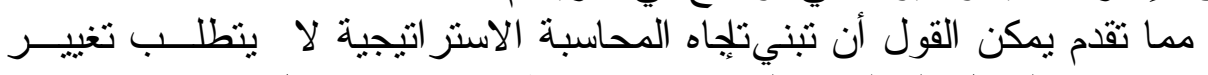

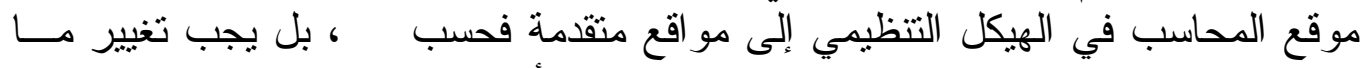
على المحاسب الإستر اتيجي عمله بالاعتماد على أساليب يمكن حصر ها لإلى فالاتي:

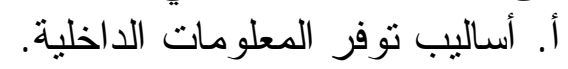
ب. أساليب توفر المعلومات الخوف الخارجية. ج. أساليب توفر المعلومات المستقبلية.

\section{أ. أساليب توفر المعلومات الداخلية}

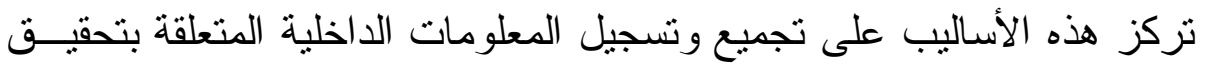

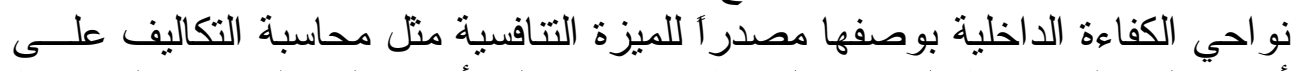

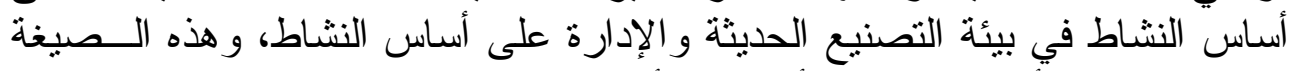

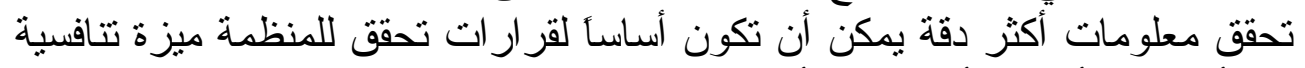

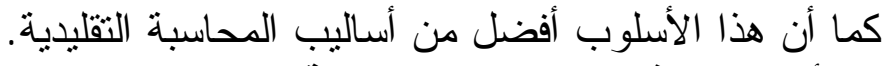

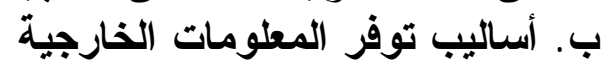

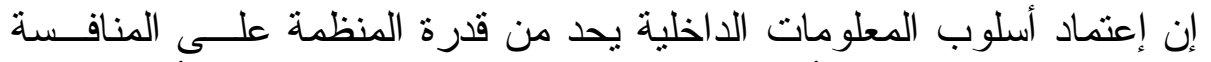

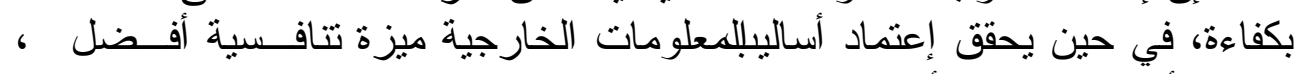
و هذه الأساليب تعتمد الأمثلة الاتية:

$$
\text { •الأسعار }
$$

أداء المنظمة مقارنة بأداء المنافسين. 


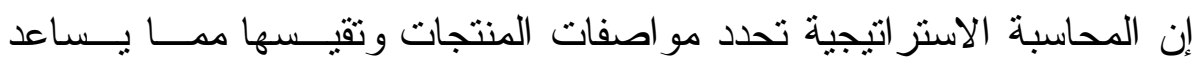
المنظمة على صياغة إستر اتيجيتها تجاه السوق، و عليه يجب على التى المحاسب تـــوفير

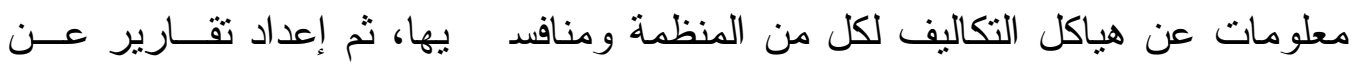

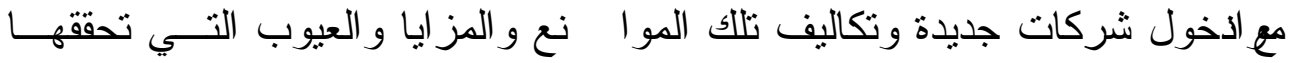
المنظمة (Brow Wich,1990, 33).

\section{ج. أساليب توفر المعلومات المستقبلية}

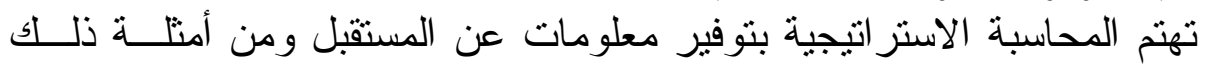

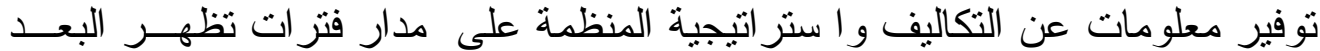

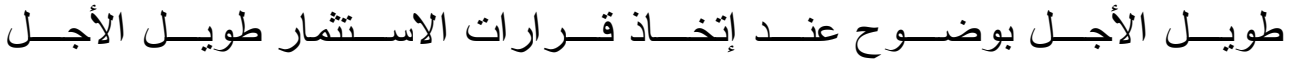
(Boquist, 1998, 55)، ومن مداخل هذه الأساليب الموازنات الر أسمالية باســتخدام

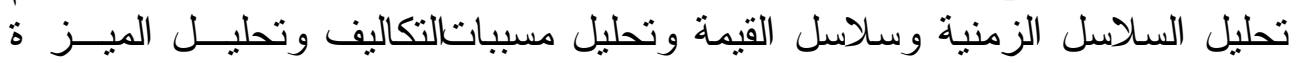
التتافسية للمنظمة و اختيار الاستر اتيجية المناسبة.

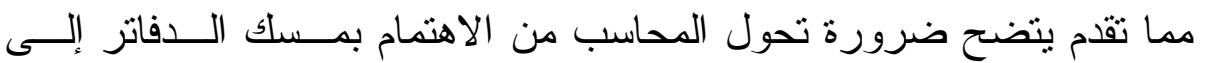

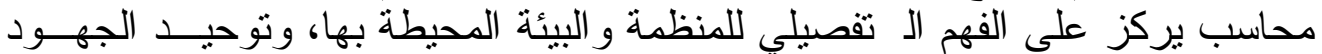

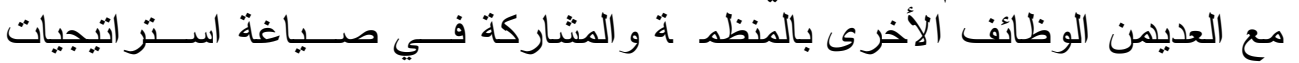

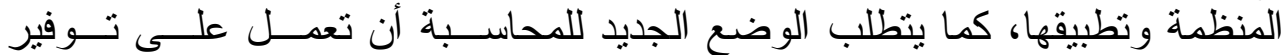

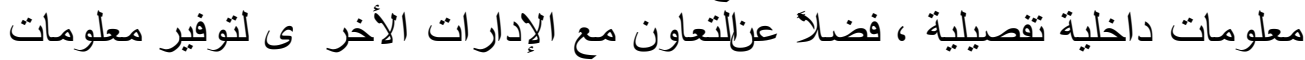
خارجية عن الـ منافسينبما يـاعد على إتخاذ قر ار ات الاستثمار الاستر اتيجية و إعداد الاد المو ازنات الر أسمالية.

\section{التعريف بالمحاسبة الاستر اتيجية r- r -}

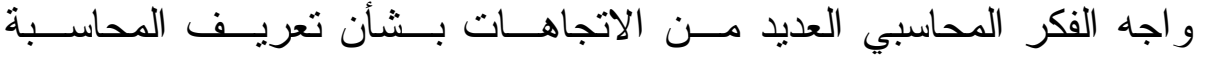
الاستز اتيجية وفيما يأتي أهم تلك الاتجيه التجاهات:

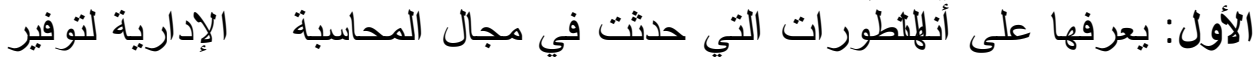

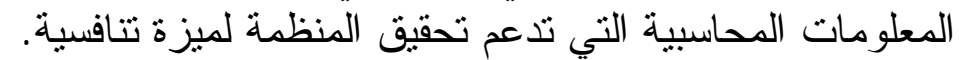

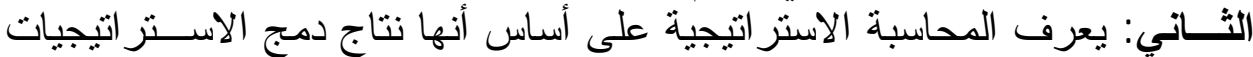

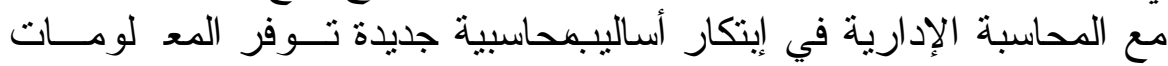
التي تدعم الإدارة الاستر اتيجية للمنظمات.

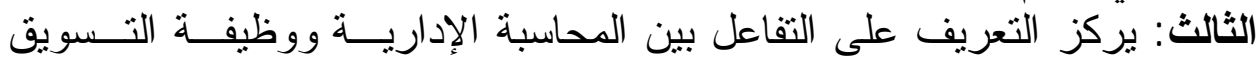

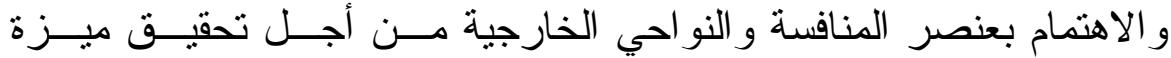

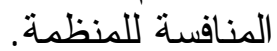

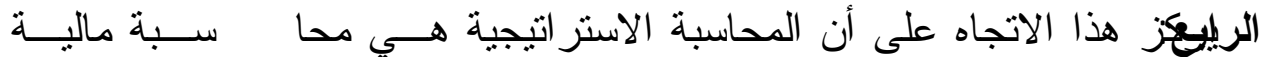

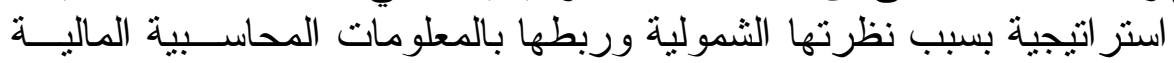
و الأهداف العليا للمنظمة من أجل تحقيق ميزة تتافسية. 


\section{ثانياً - المحاسبة الإستر اتيجية و أثرها على المعلومات المحاسبية}

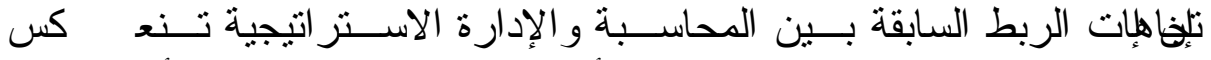

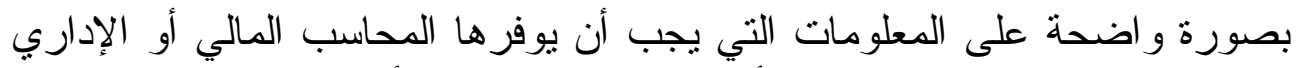

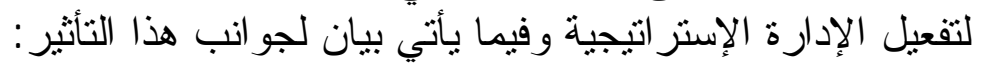

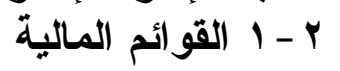

إن المعلومات المحاسبية التي تتضمنها القو ام المالية و التـــي نــص المعيــار

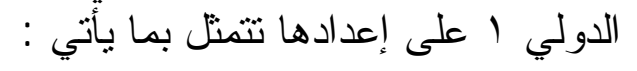

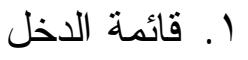

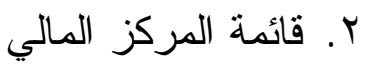

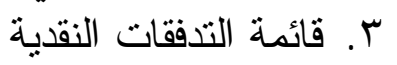
ع. قائمة التغير ات في حقوق التوفات المساهمين

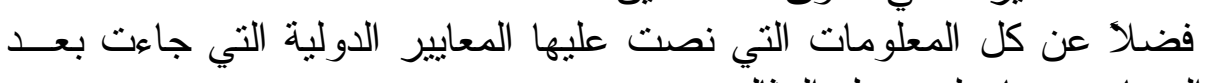
هذ ا المعيار ومنها على سبيل المنثال:

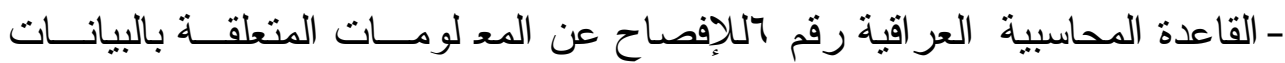

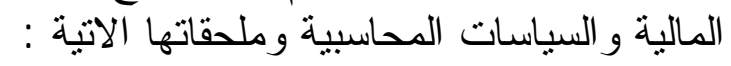

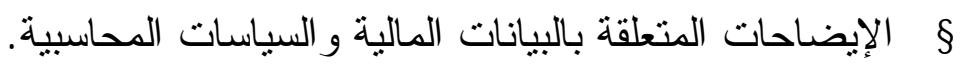
محتويات التقرير السنوي للإدارة. B

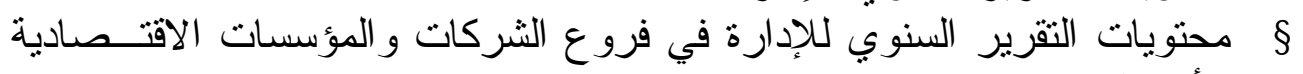
الأجنبية.

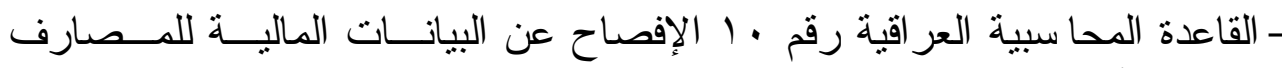

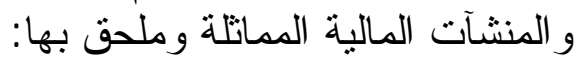
الإيضاحات المتعلقة بالبيانات المالية و السياسات المحاسبية B محتويات التقرير السنوي للإدارة. B

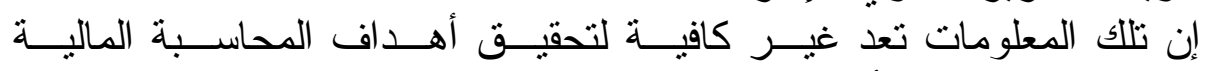

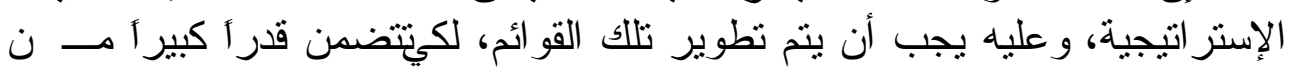

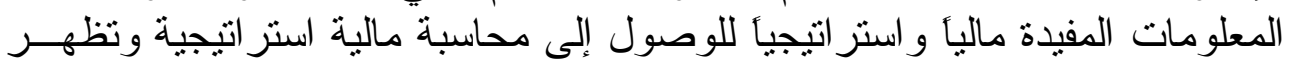
تلاك الاستفادة في: المعات أ. دعم اختيار وتحليل نقاط القوة و الضعف و والفرة الفر و التحديات.

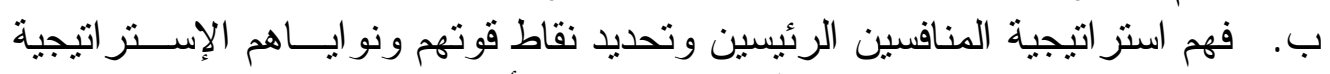

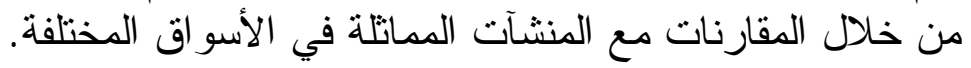
ج. فهم موقف العملاء الرئيسين و احتياجاتهم الحالية و المستقبلية.

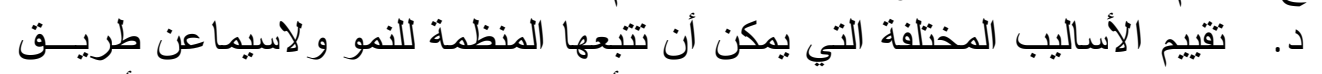

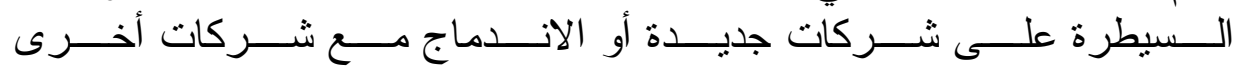
.(Johnson and Scholes, 1998, 98) 


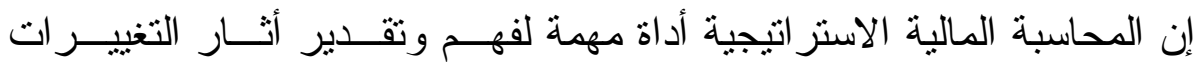

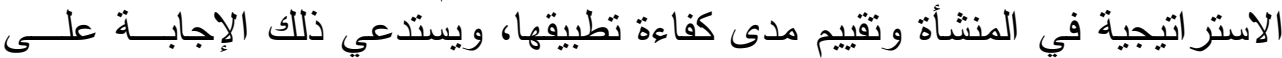

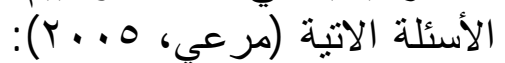

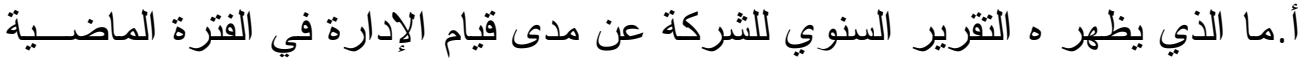

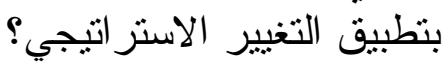

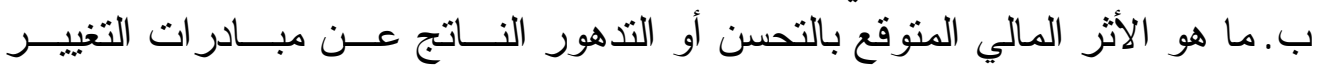
الاستر اتيجي الحالية على المستويين الداخلي و الخارجي للمنشاة؟

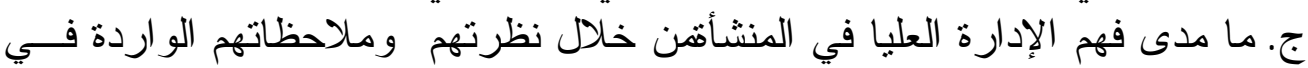

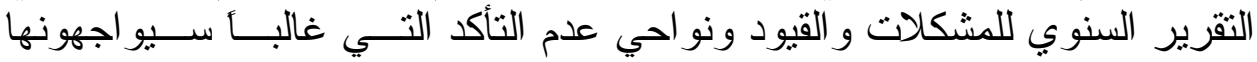
مستقبلا عند تطبيق التغيير الاستز اتيجي؟

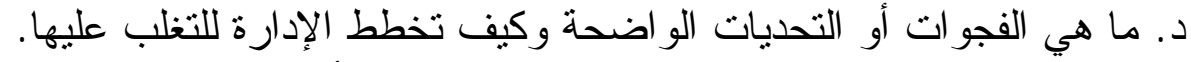

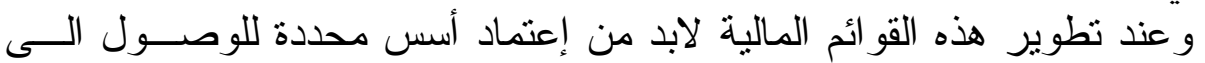

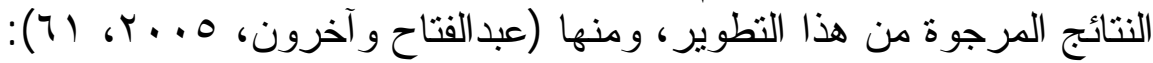

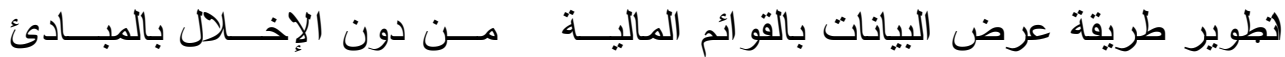
و الأسس المحاسبية المعدة على أساسها.

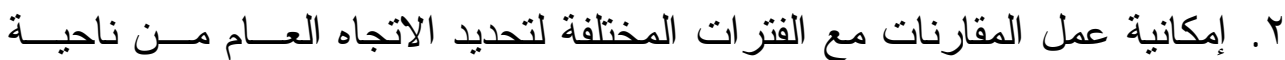

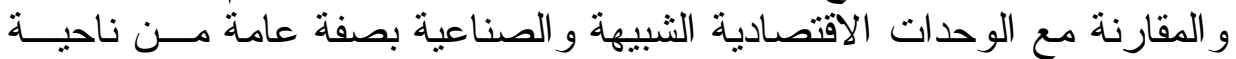

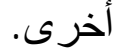

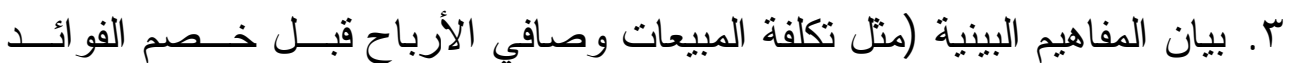

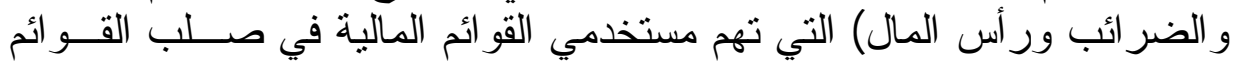
المالية وبصورة و واضحة.

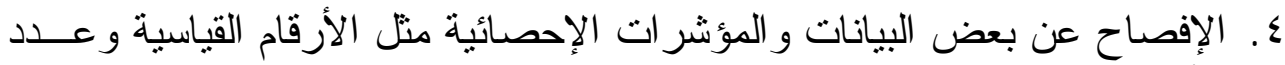

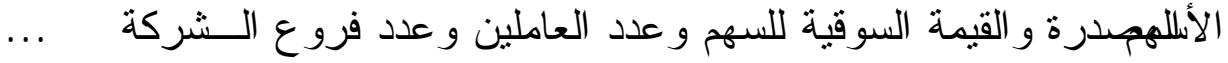

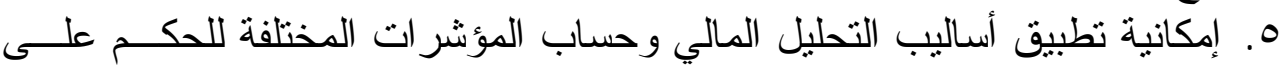

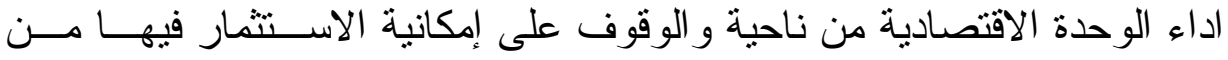

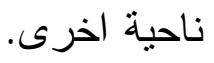

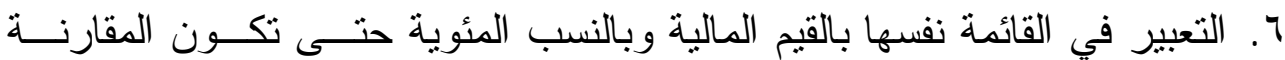

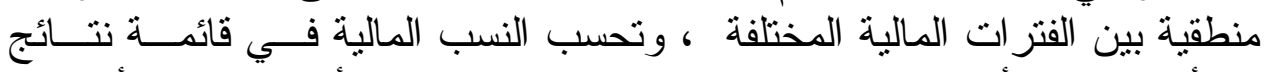

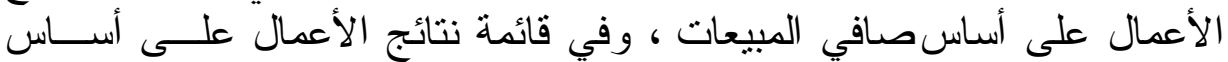

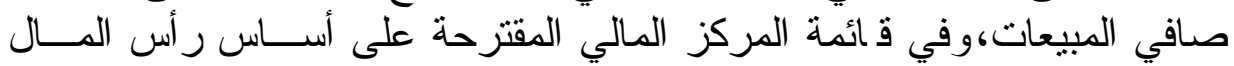

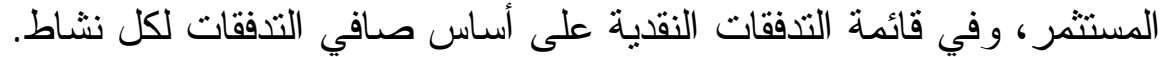

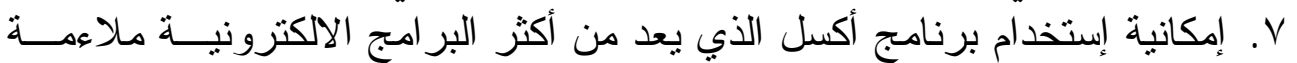

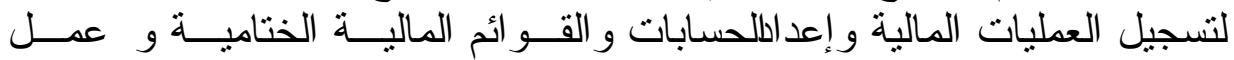
التحليلات المالية و إعداد الموازنات التخطيطية و التنبؤ بالتدفقات النقدية. 
و على الرغم من الفائدة الكبيرة لنسب التحليل المالي التي يمكن صياغتها مــن التهن

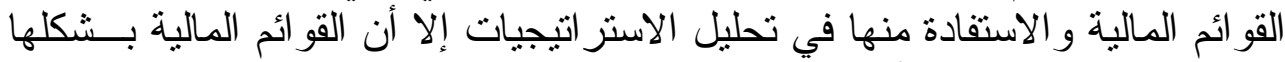

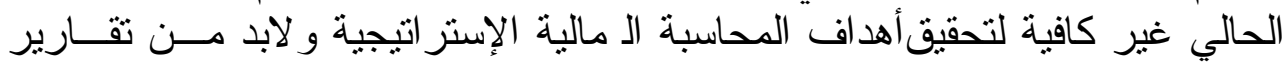

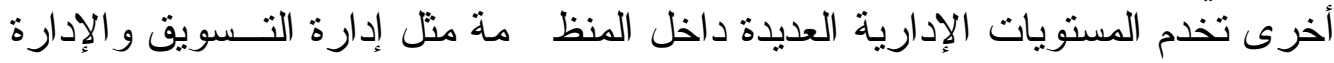
الفنية (الإنتاج) و غير ها.

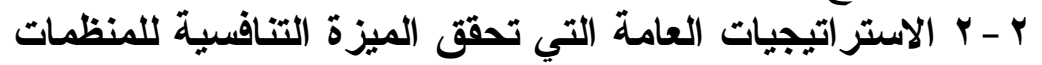

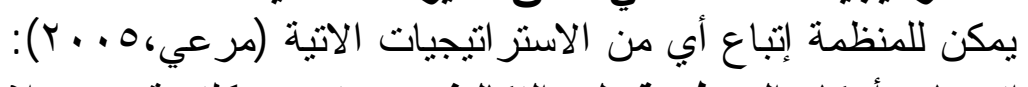

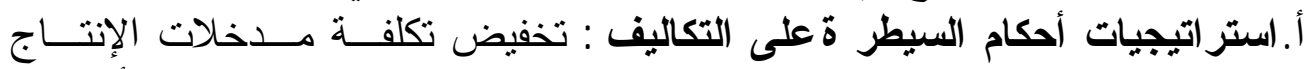

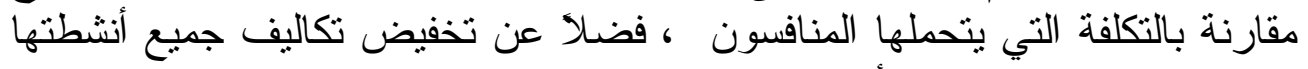

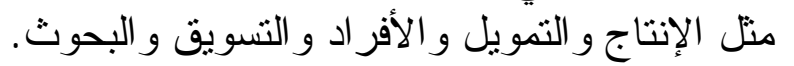

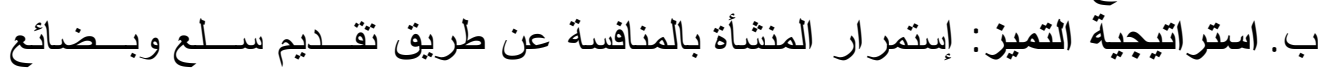

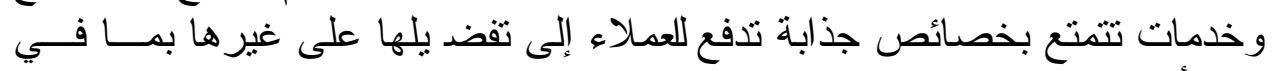

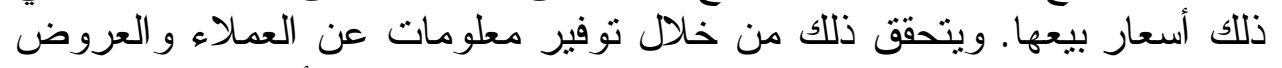

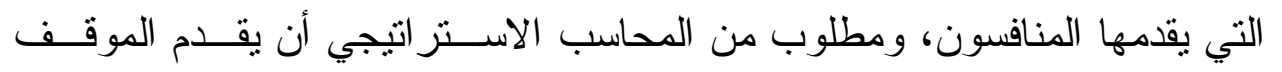

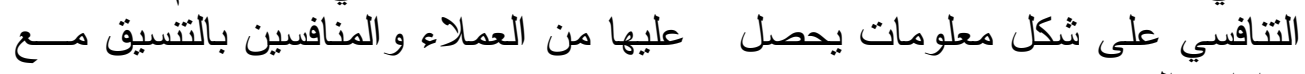
إدارة التسويق. ج. استراتيجية التركيز: إختيار شريحة معينة من العملاء و التركيز على احتياجاتهم

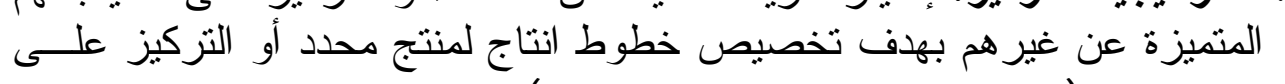
سوق معين (Wheelen and Hunger, 2002,122).

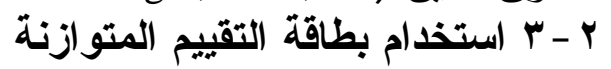

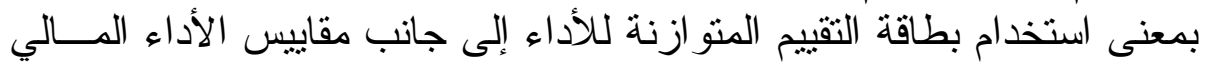

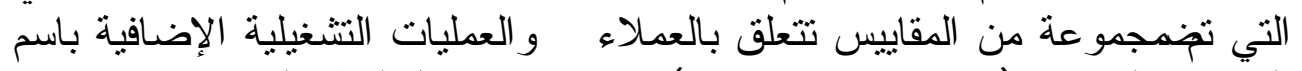

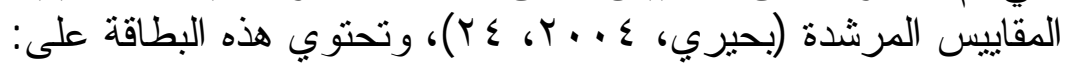

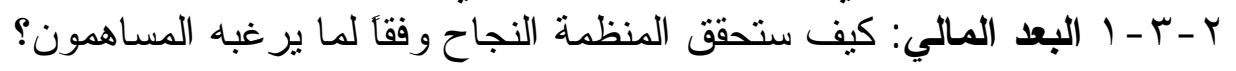

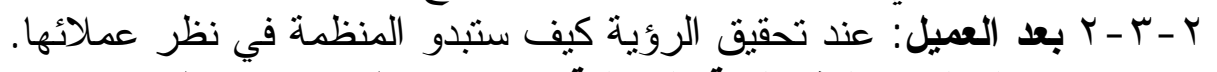

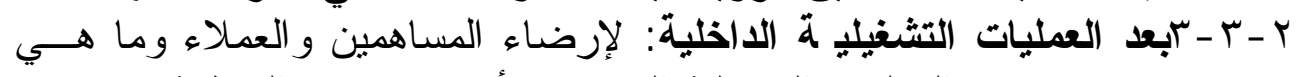

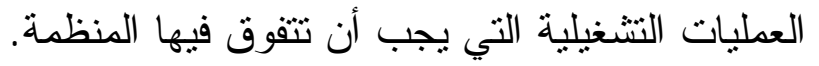

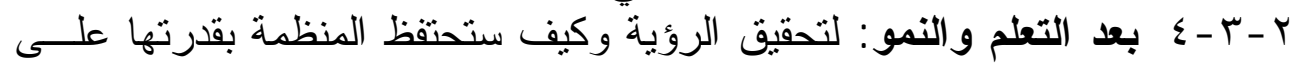
التغير و التحسن.

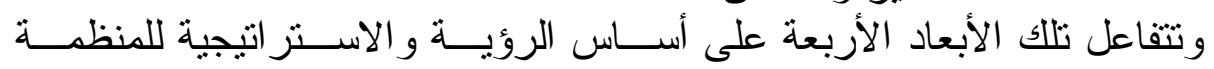

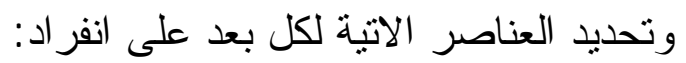

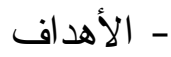

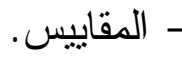
- المستهدف. - المفين. - المبادر ات (الديسطي، س. . . ب ، 1 1). 


\section{r. واقع التطبيق العملي للمحاسبة الإستراتيجية في البيئة العراقية}

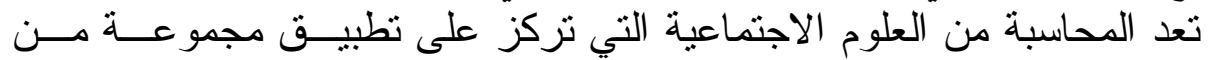

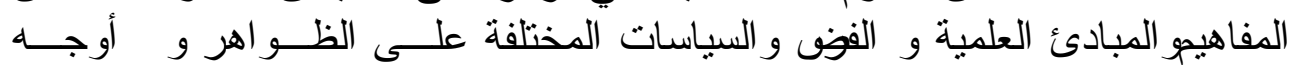

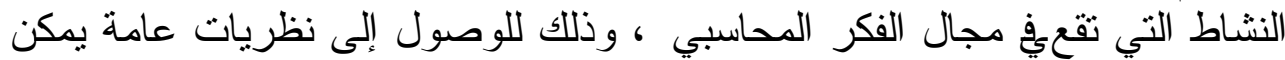

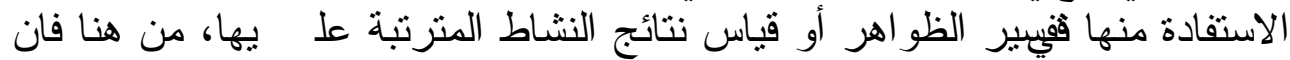

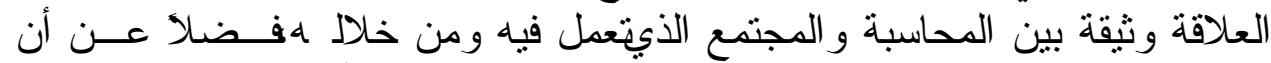

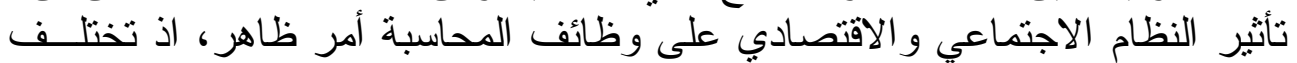

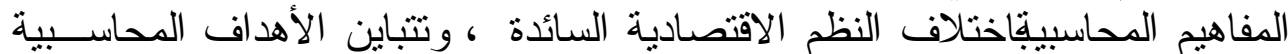

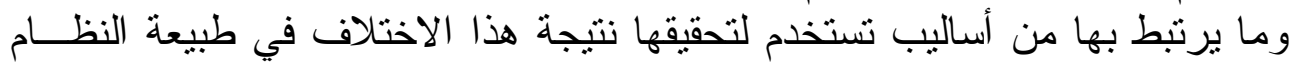
اقتصادي و الاجتماعي السائد.

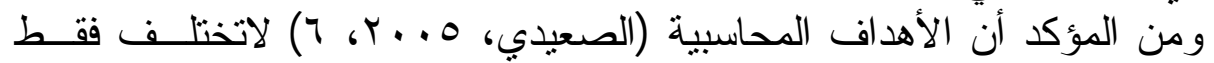

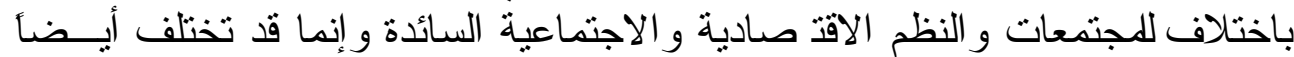

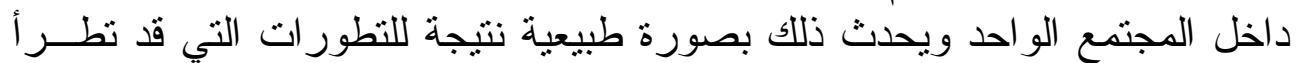

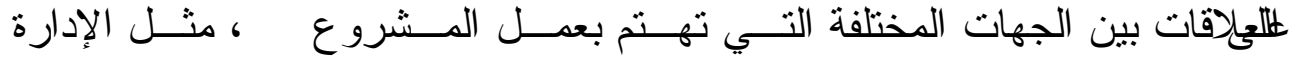

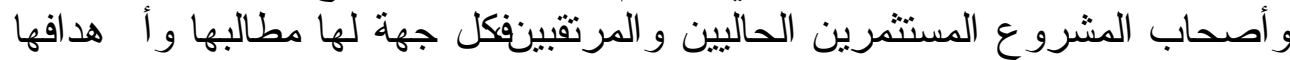

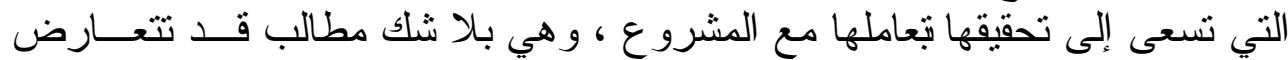

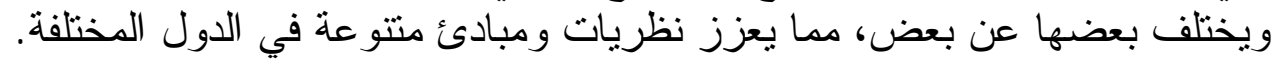

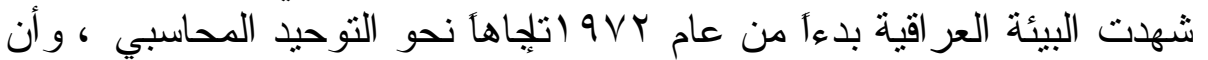

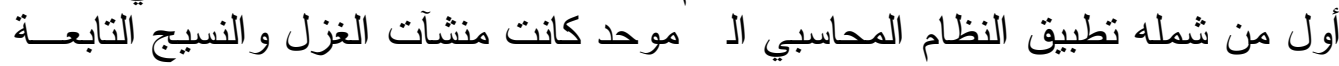

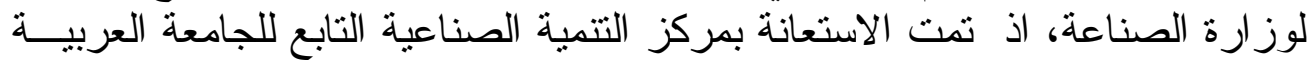

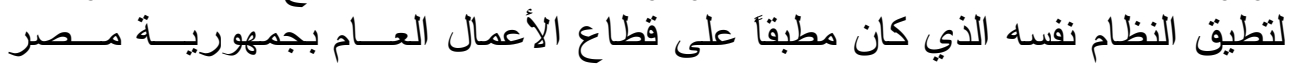

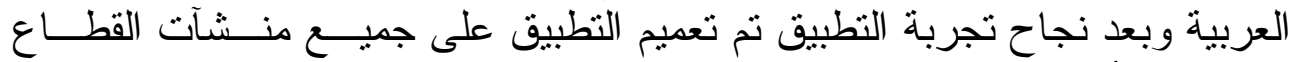

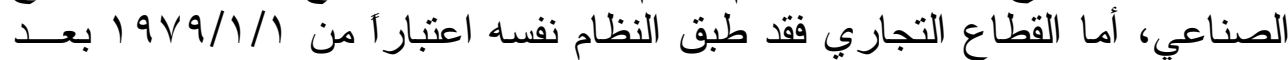

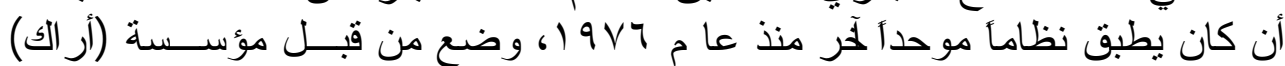

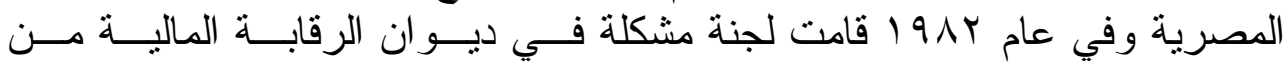

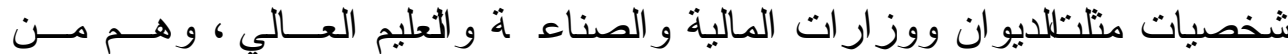

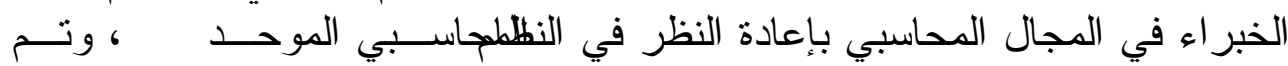

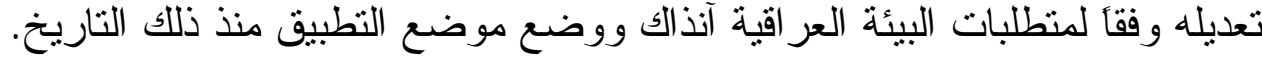

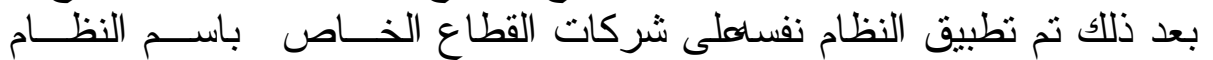

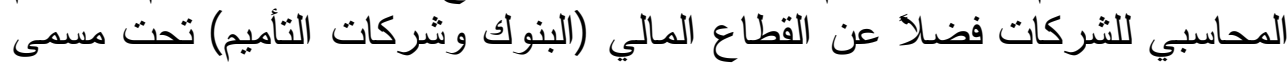
النظام المحاسبي للمصارف وشركات اللات التأميج.

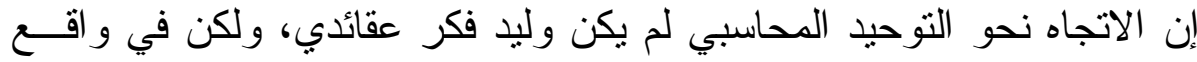

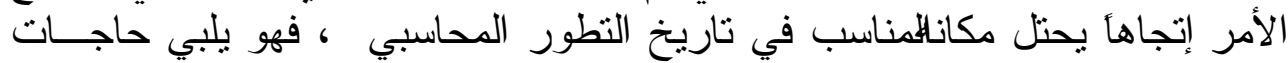

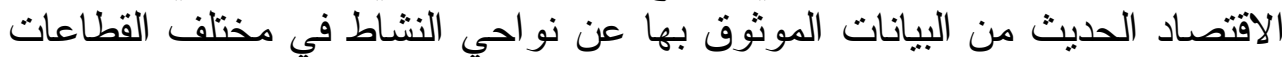

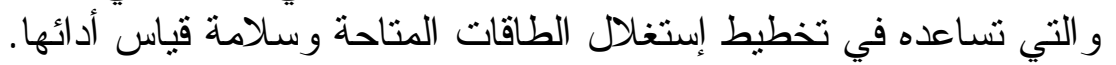




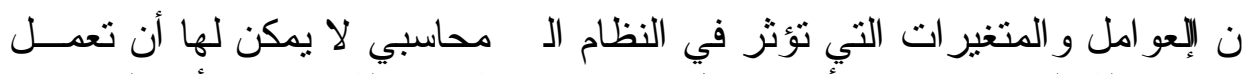

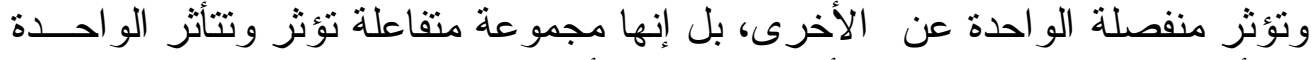

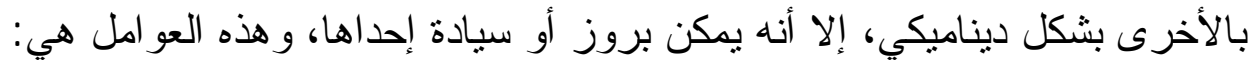

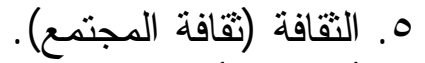
T. أسو اق رأس المال و التمويل. 1. العو امل البيائية. 1. 1. العوامل البيانئي.

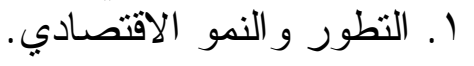

لغرض التعرف على تطبيق مفهوم المحاسبة الاستر اتيجية في البيئة العر اقيـــة فان الأمر يتطلب الإجابة عن النساؤلين الاتينين:

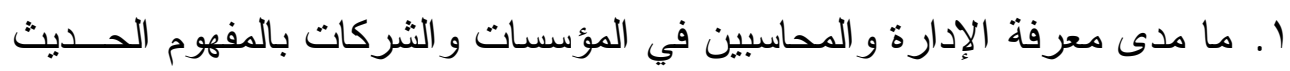

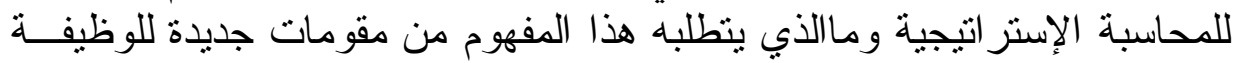
المحاسبية

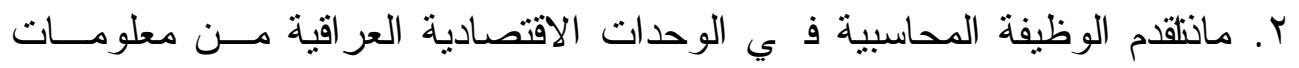

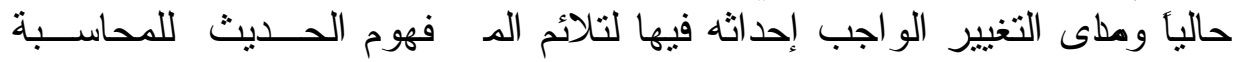
الاستر اتيجية.

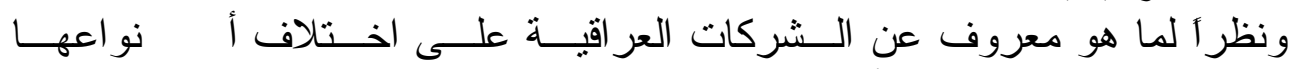

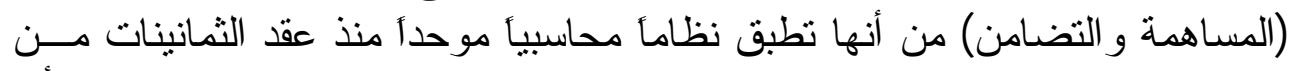

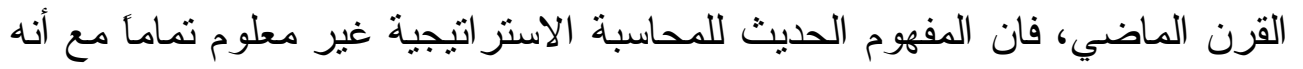

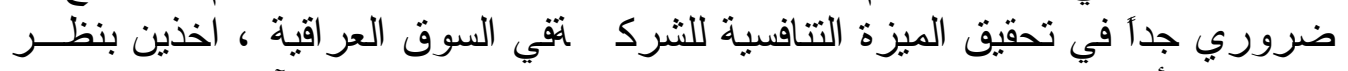

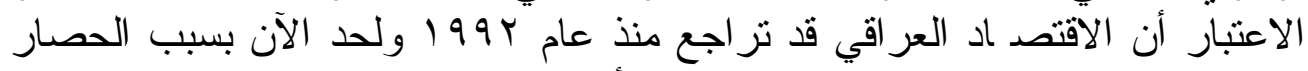

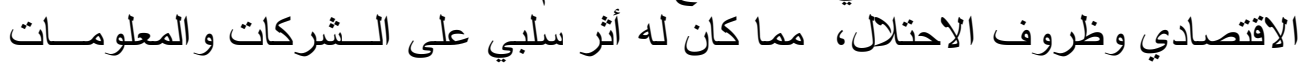
التي تنتجها القو ائم المالية.

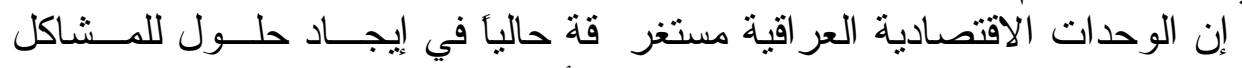

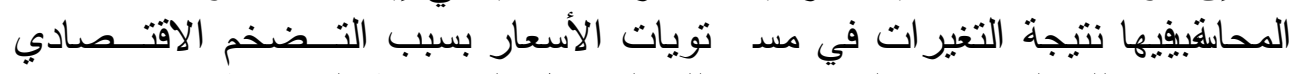

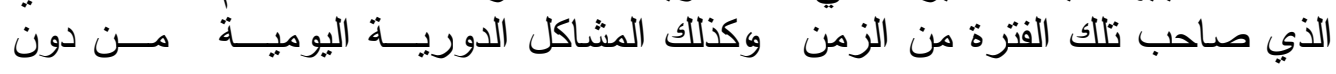

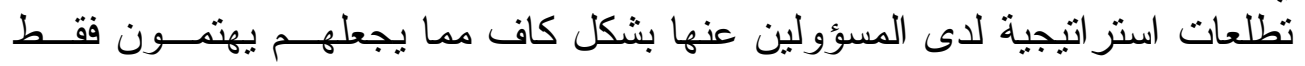

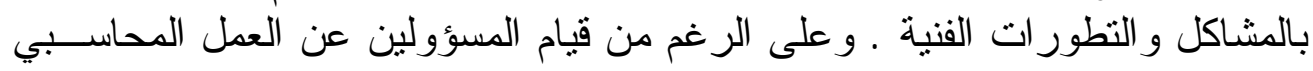

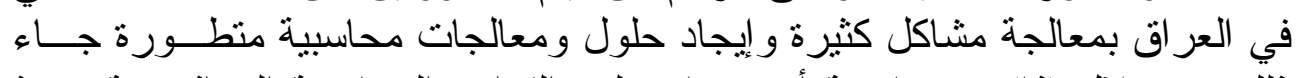

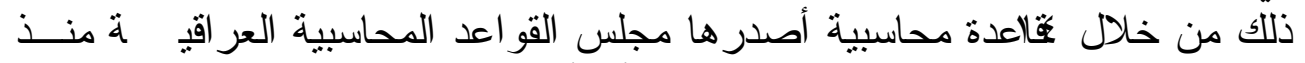

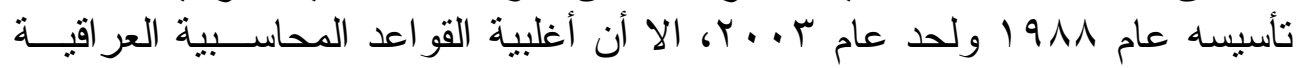

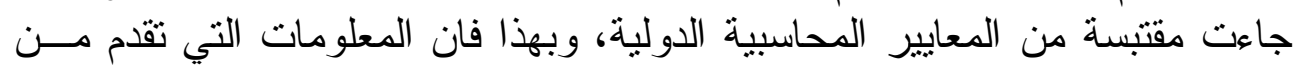

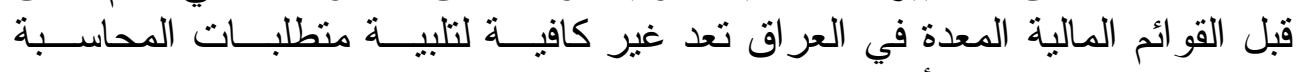

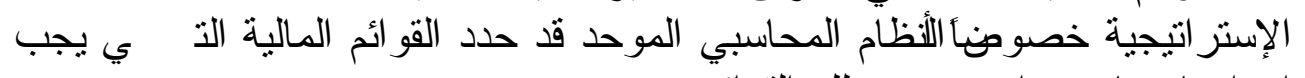

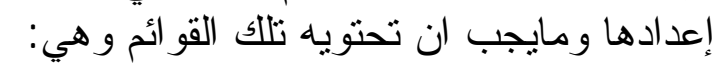

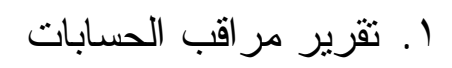

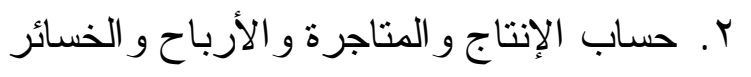




$$
\begin{aligned}
& \text { r. حساب العمليات الجارية وكثف النشاط الجاري }
\end{aligned}
$$

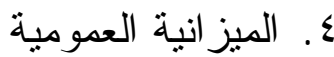

$$
\begin{aligned}
& \text { ○. كثن التذفق النقدي } \\
& 7 \text { ا ل الكثوفات التفسيرية }
\end{aligned}
$$

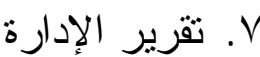

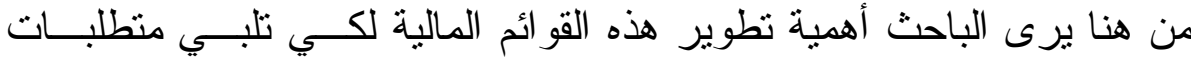

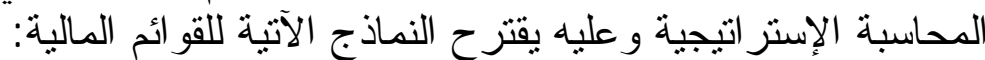

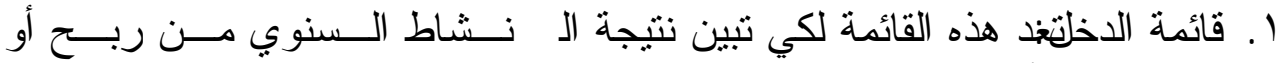

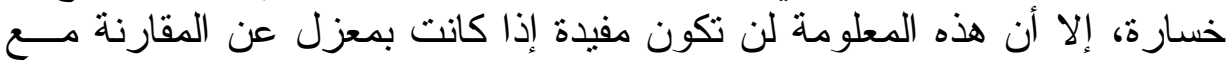

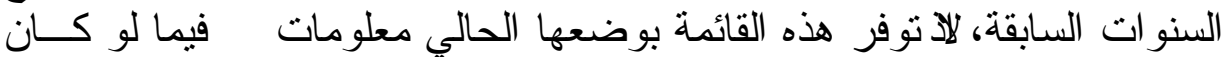

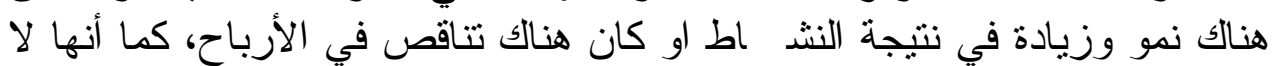

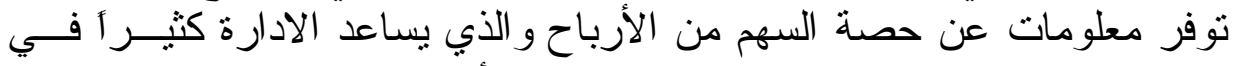

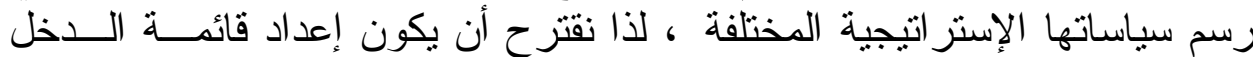
لأغر اض المحاسبة الإستر اتيجية على وفق الإنموذج الأني:

(*)

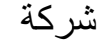
قائمة الدخل

\begin{tabular}{|c|c|c|c|c|c|c|}
\hline \multicolumn{4}{|c|}{ سنوات المقارنة } & \multicolumn{2}{|c|}{ السنة المالية } & \multirow{2}{*}{ التفاصيل } \\
\hline$\ldots . .$. & 20 & 20 & 20 & $\%$ & 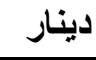 & \\
\hline & & & & & $\mathrm{xxx}$ & إير اد المبيعات ( ) \\
\hline & & & & & & ت تكاليف الانتاج \\
\hline & & & & & $\mathrm{xxx}$ & تكاليف مباشرة \\
\hline & & & & & $\mathrm{xXX}$ & | تكاليف غير مبانشرة \\
\hline & & & & & $\mathrm{xxx}$ & إجمالي تكاليف الإنتاج خلال الفترة \\
\hline & & & & & $\mathrm{Xx}+$ & + مخزون إنتاج غير تام أول الفترة \\
\hline & & & & & $\mathrm{xx}^{-}$ & - مخزون إنتاج غير تام أخر المدة \\
\hline & & & & & $\mathrm{XXX}$ & تكلفة الإنتاج التام خلال الفترة \\
\hline & & & & & $\mathrm{Xx}+$ & + مخزون الإنتاج التام أول المدة \\
\hline & & & & & XX- & - مخزون الإنتاج التام آخر المدة \\
\hline
\end{tabular}

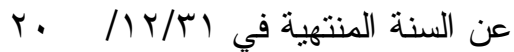


ماقبله

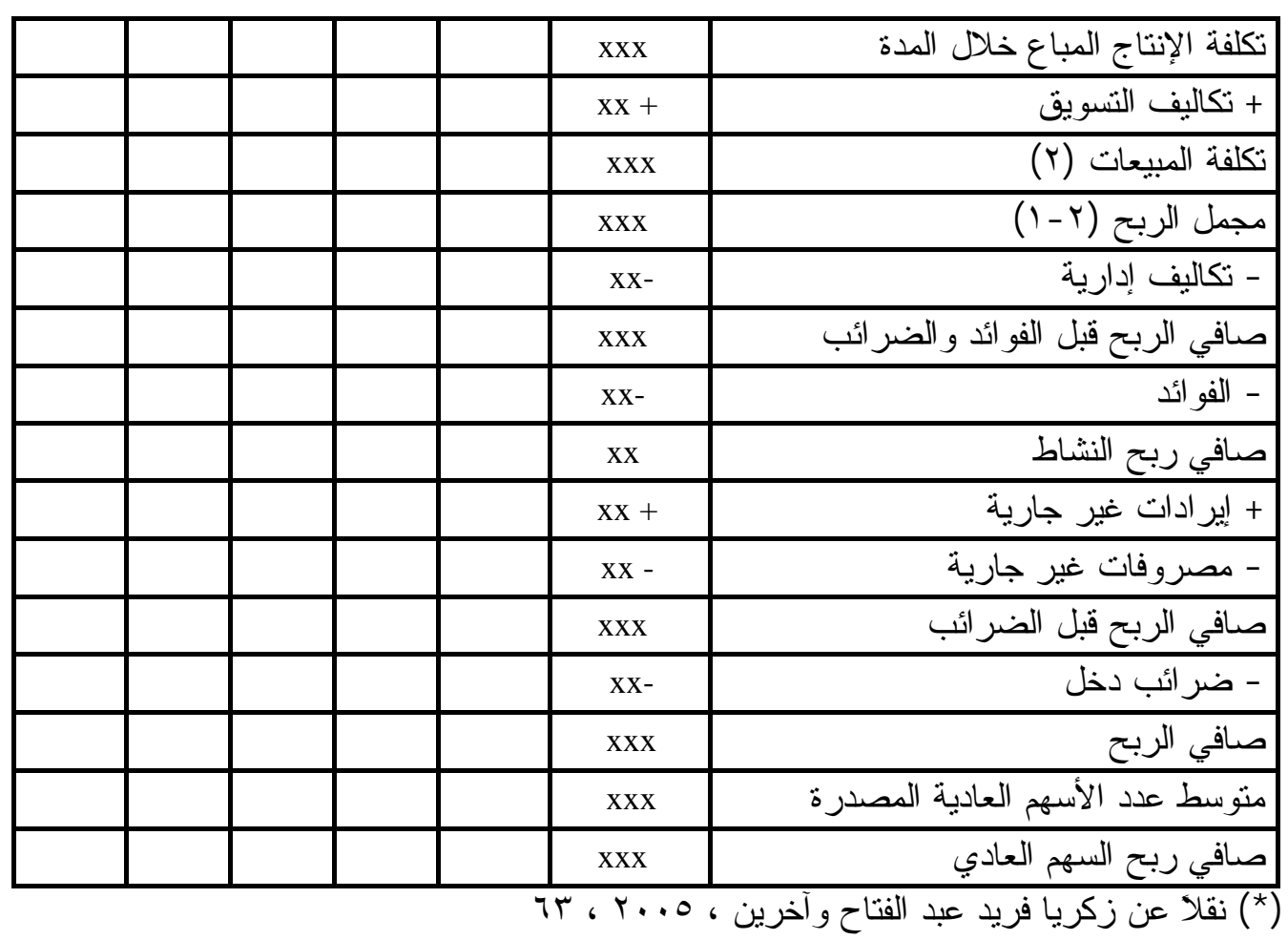

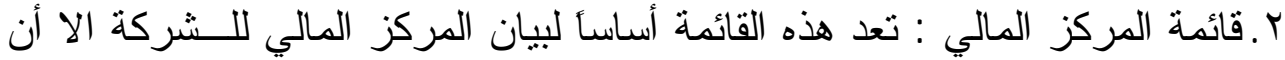

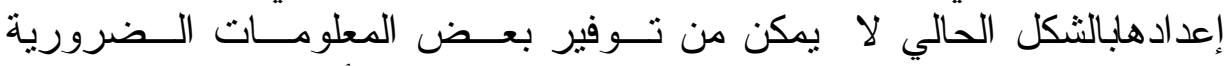

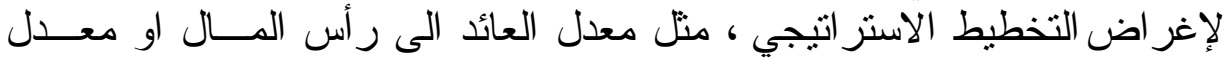

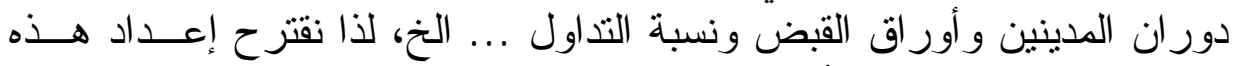

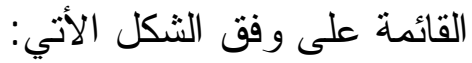




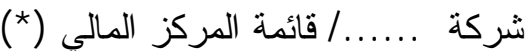

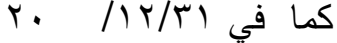

\begin{tabular}{|c|c|c|c|c|c|c|}
\hline \multicolumn{4}{|c|}{ سنوات المقارنة } & \multicolumn{2}{|c|}{ السنةّة المالية } & \multirow{2}{*}{ التفاصيل } \\
\hline ... & 20 & 20 & 20 & $\%$ & دينار & \\
\hline & & & & & & او لا : مكونات رأس المال المستخمر : \\
\hline & & & & & $\mathrm{xxx}$ & مخزون سلعي \\
\hline & & & & & $\mathrm{xxx}$ & مدينون و اور اق قبض (صافي) \\
\hline & & & & & $\overline{\mathrm{xxx}}$ & حسابات مدينة مختلفة \\
\hline & & & & & $\mathrm{xxx}$ & نقدية بالصندوق و البنوك \\
\hline & & & & & $\mathrm{xxx}$ & مجموع الاصول المتداولة \\
\hline & & & & & & خصوم متداولة: \\
\hline & & & & & $\mathrm{xxx}$ & بنوك دائنة \\
\hline & & & & & $\mathrm{xxx}$ & دائنون واور اق دفع \\
\hline & & & & & $\mathrm{xxx}$ & حسابات دائنة مختلفة \\
\hline & & & & & $\mathrm{xxx}$ & مجموع الخصوم المتداولة \\
\hline & & & & & $\mathrm{xxx}$ & رأس المال العامل \\
\hline & & & & & $\mathrm{xxx}$ & اصول ثابتة \\
\hline & & & & & $\mathrm{xxx}$ & مجموع مكونات رأس المال المستثمر \\
\hline & & & & & & مصادر تمويل رأس المال المستثمر \\
\hline & & & & & & حقوق الملكية \\
\hline & & & & & $\mathrm{xxx}$ & رأس المال \\
\hline & & & & & $\mathrm{xxx}$ & إحتباطيات وأرباح مرحلة \\
\hline & & & & & $\mathrm{xxx}$ & مخصصات الاهلاك \\
\hline & & & & & $\mathrm{xxx}$ & مجموع حقوق الملكية \\
\hline & & & & & $\mathrm{xxx}$ & قروض طويلة الاجل \\
\hline & & & & & $\mathrm{xxx}$ & مجموع مصادر تمويل رأس المال المستثمر \\
\hline & & & & & $\mathrm{xxx}$ & نسبة التداول \\
\hline & & & & & $\mathrm{xxx}$ & نسبة السيولة السريعة \\
\hline & & & & & $\mathrm{xxx}$ & نسبة حقوق الملكية \\
\hline & & & & & $\mathrm{xxx}$ & معدل دور ان المدينين وأور اق القبض \\
\hline & & & & & $\mathrm{xxx}$ & معدل العائد على حقوق الملكية \\
\hline & & & & & $\mathrm{xxx}$ & معدل العائد على رأس المال \\
\hline
\end{tabular}

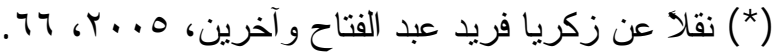


r.قائمة التدفقات النقدية : بعد الانتهاء من إعداد خائمة المركز المالي ) نقوم بإعداد

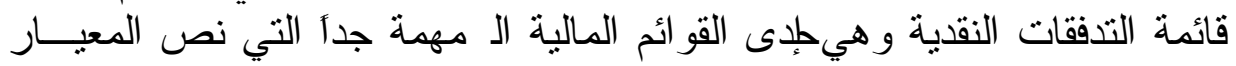

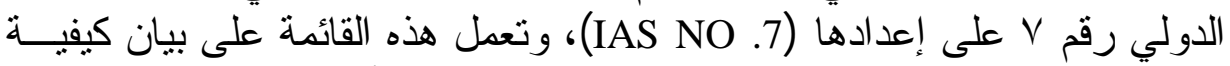

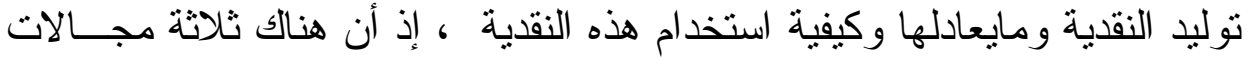

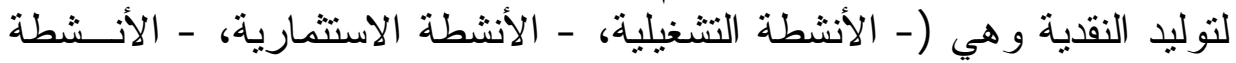

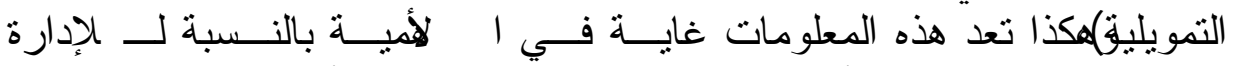

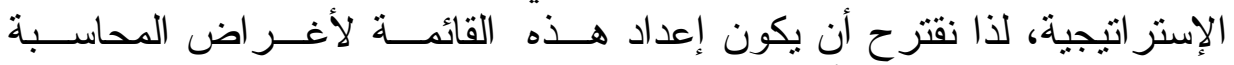
الإستر اتيجية على وفق الأنموذج الآتي: لأنية إنى

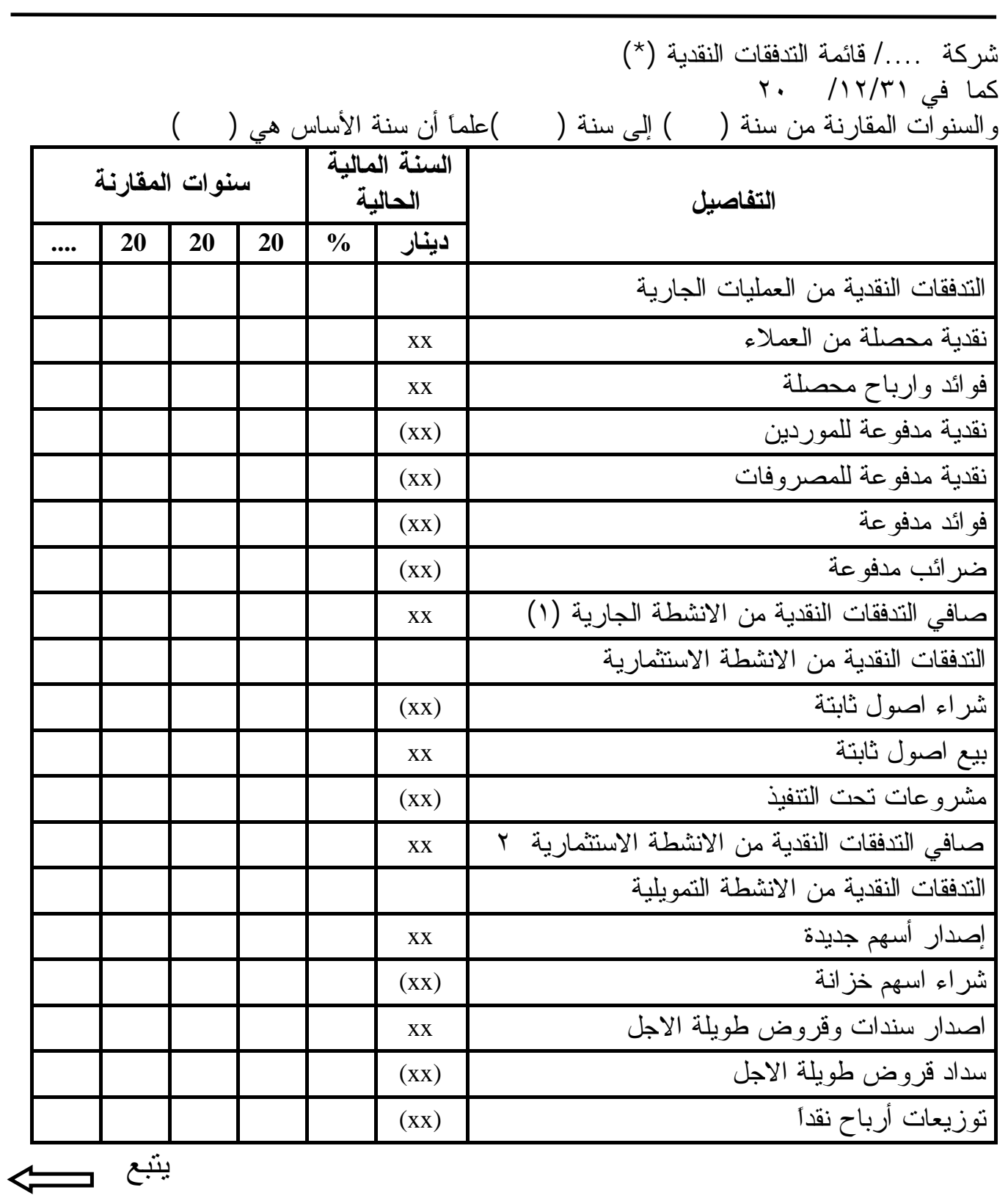


ماقبله

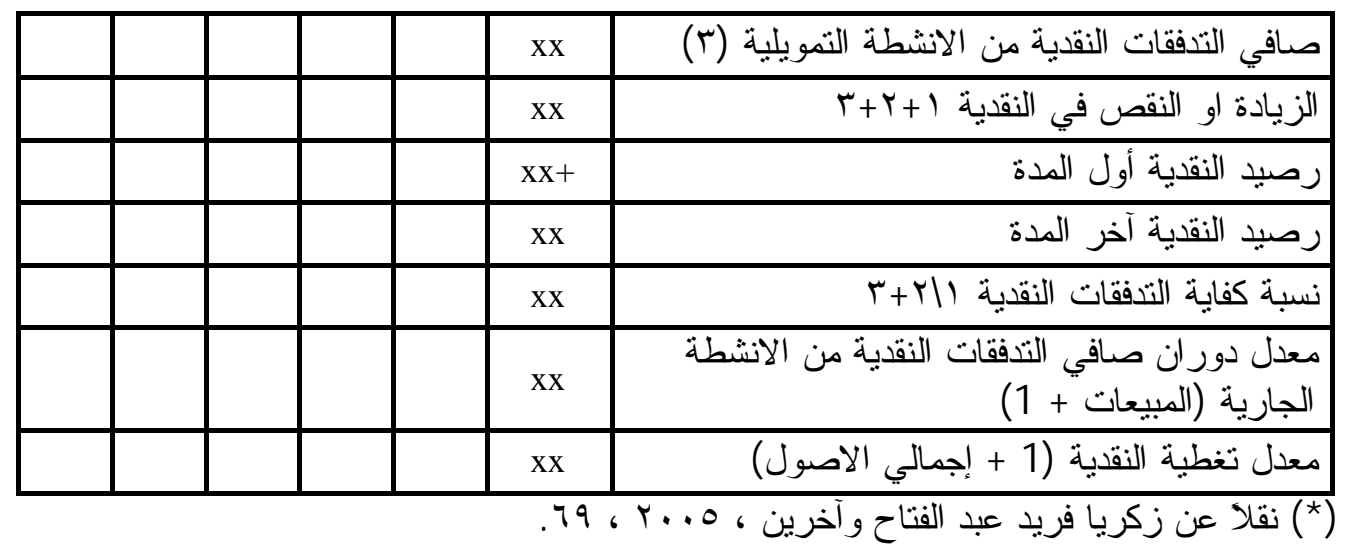

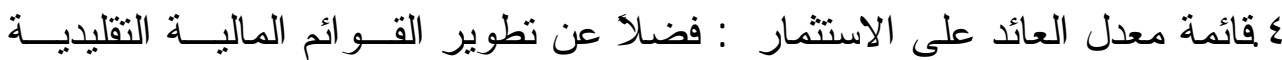

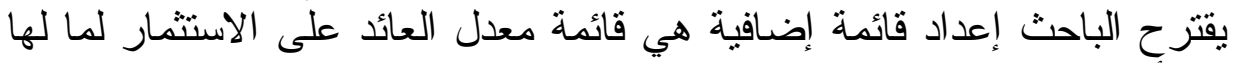

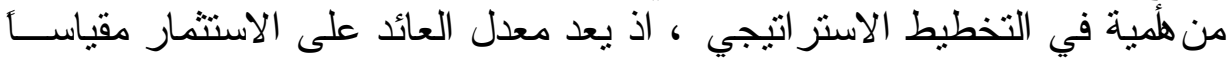

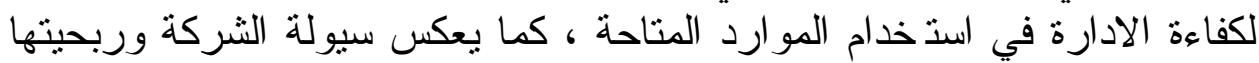

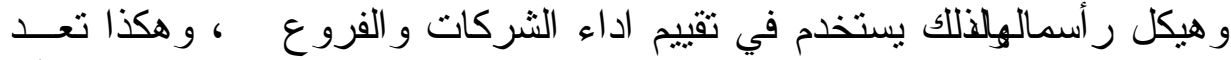

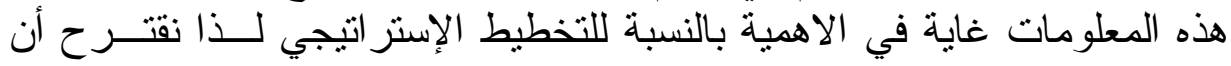

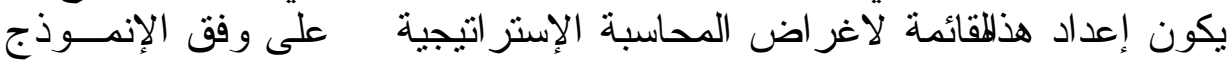
الاتي:

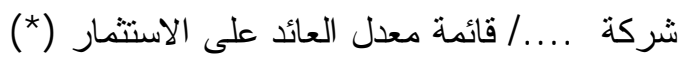

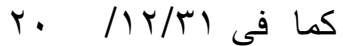

\begin{tabular}{|l|c|c|c|c|c|}
\hline \multicolumn{2}{|c|}{ و السنو } \\
\hline \\
\hline
\end{tabular}


ماقبله

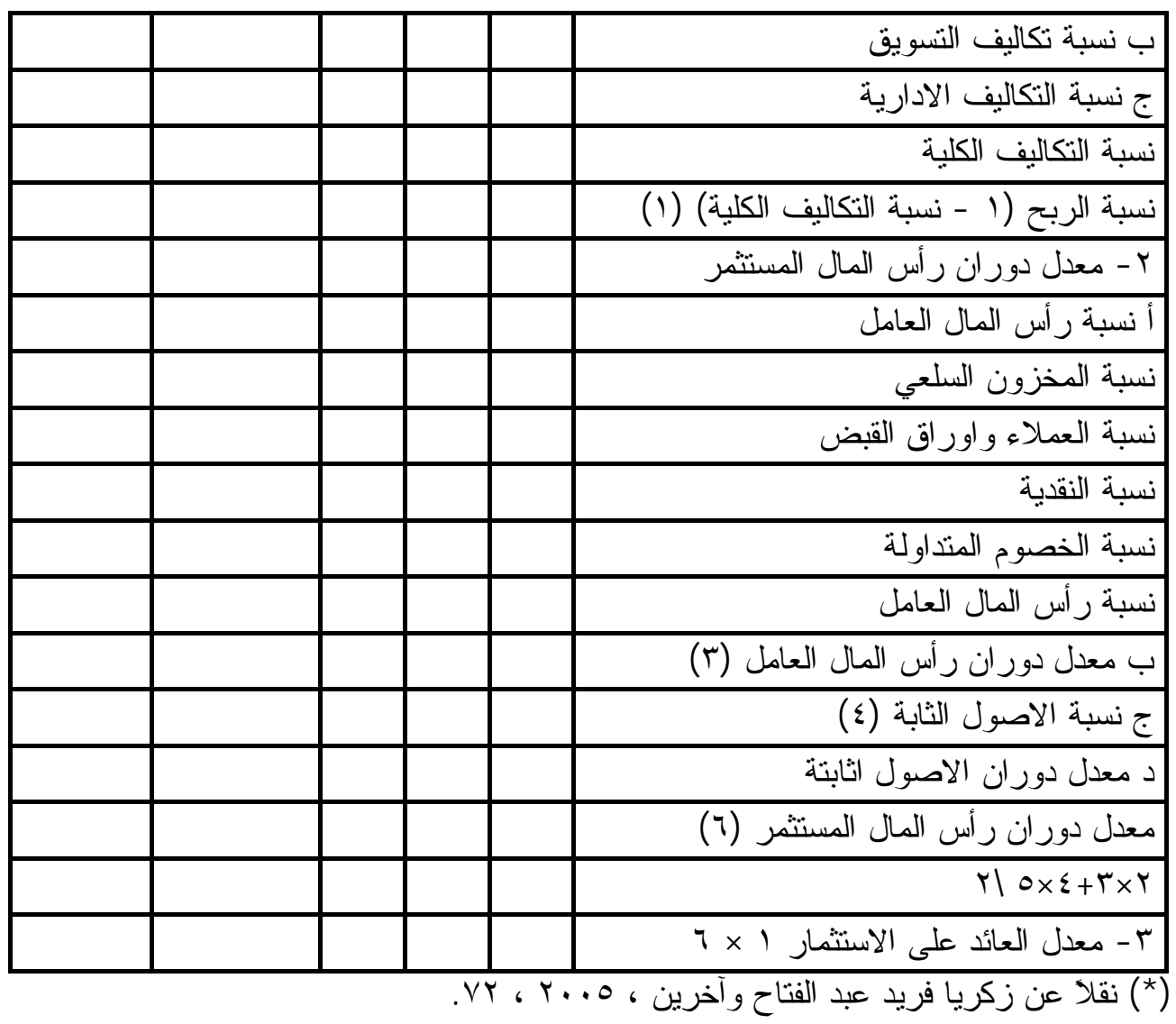

النتائج و التوصيات

1. هنالك ثلاثة إتجاهات في تعريف المحاسبة الاستر اتيجية:

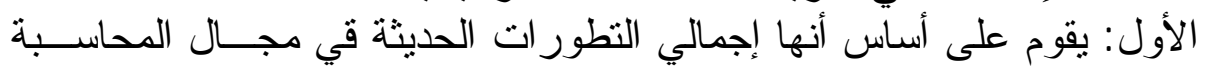

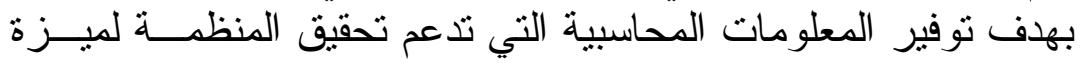

تنتافسية.

الثاني: يقوم على أساس دمج أدب الاستر اتيجيات مع المحاسبة.

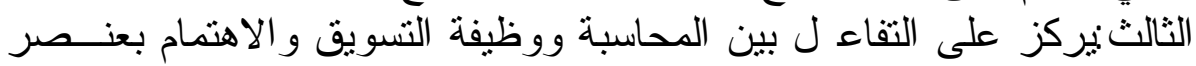

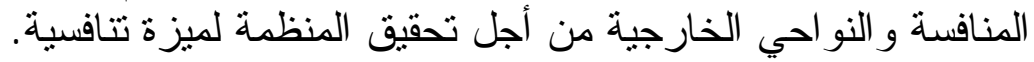
كما أن الفكر المحاسبي تضمن ثلاثة مداخل لتفسير المحاسبة الاستراتيجية:

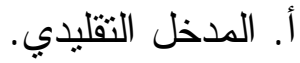

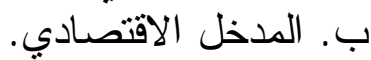

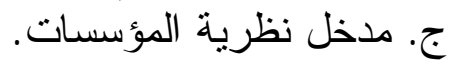


r. لتفعيل دور الإدارة الاستر اتيجية لابد من تغيير دور المحاسبة إلى التركيز علـى التى الته

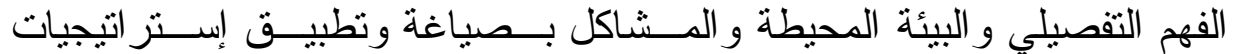
المنشأة.

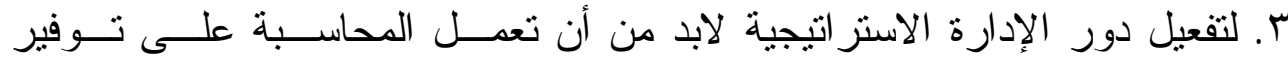

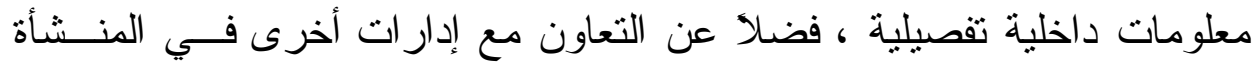

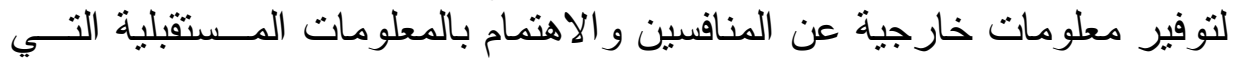

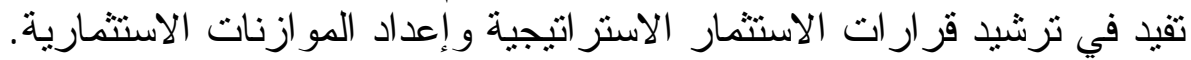

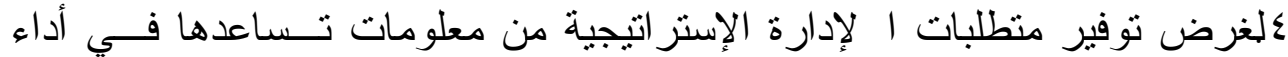

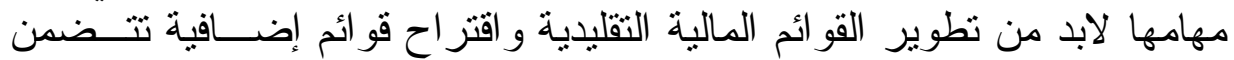

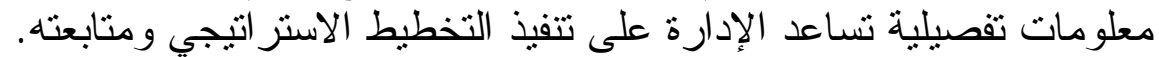

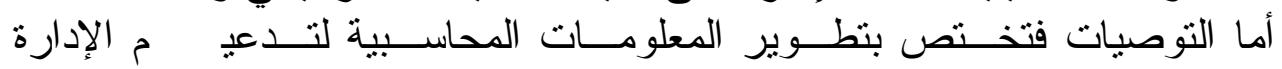
الاستر اتيجية وهي

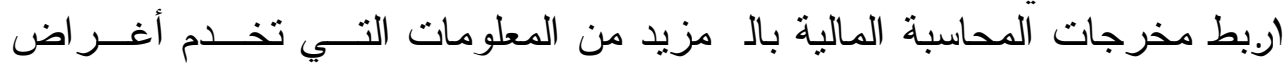
التحليل الاستر اتيجي. r. توفير معلومات عن خفض التكاليف و التحكم في تكـــاليف الإنتـــاج و التــسويق

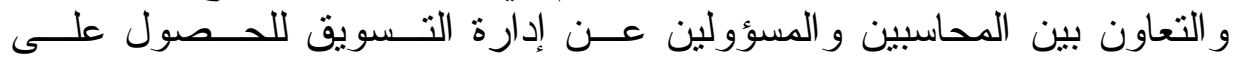
المعلومات عن هياكل تكاليف المنافينين.

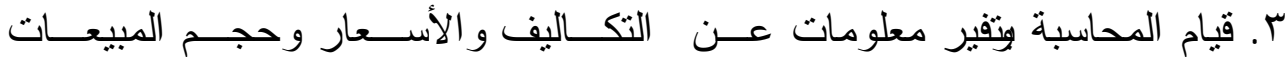

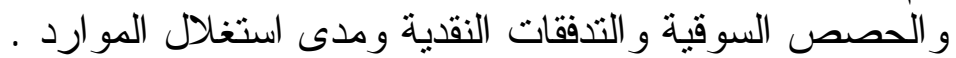

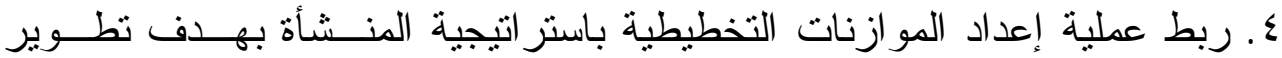
قدر ات إنتاجية جديدة.

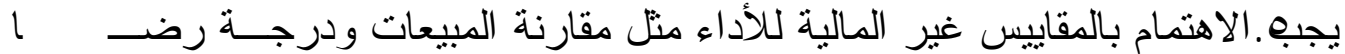
العملاء وو لائهم للمنشاة.

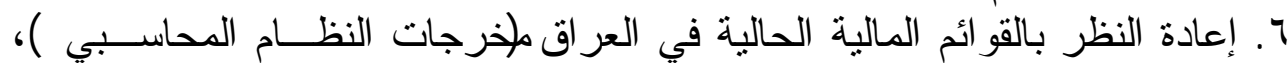

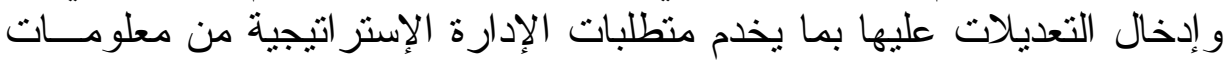

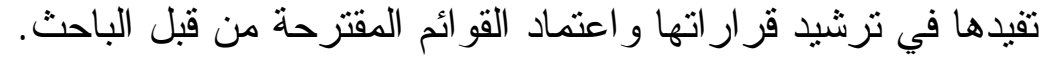

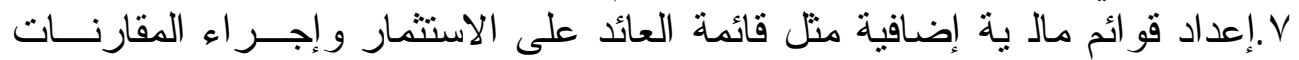

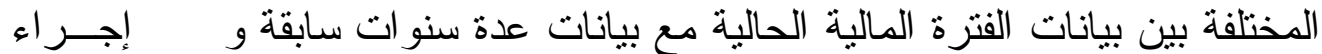

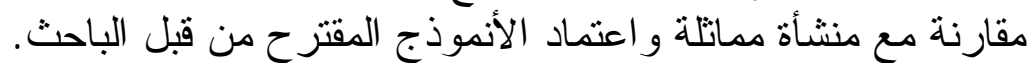

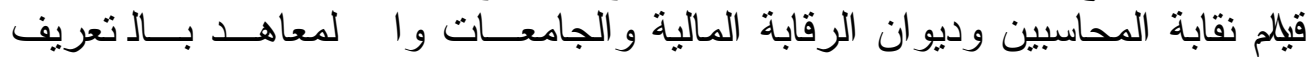

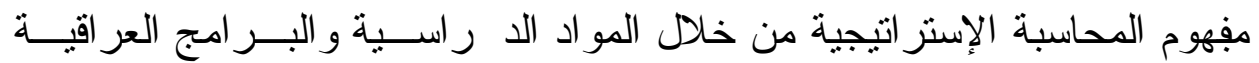
التدريبية. 


\section{أولاًا - المر اجع باللغة العزبية}

ا ـ برا اهيم احمد الصعيدي، د دراسات في نظم المعلومات المحاسـبية و الإداريــة ، مطبعــة دار

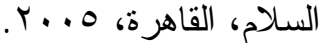

r. إسماعيل محمد السيد، الإدارة الإستر اتيجية مفــاهيم وحــالات تطبيقيــة، الــــار الجامعيــة

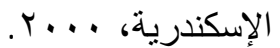

بزكريا فريد عبد الفتاح، و آخرون، د راسات في نظرية المحاسبة، مكتبة عين شمس، القاهرة ، r...

ع. فـلاح حسن الحسيني، الإدارة الإستر اتيجية مفاهيمها مداخلها عملياتها المعاصــرة، دار و وائـلـل

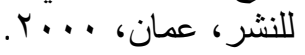

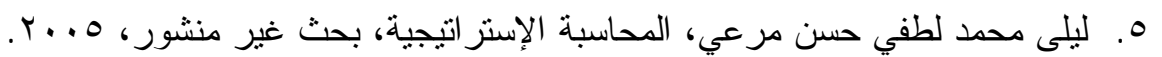

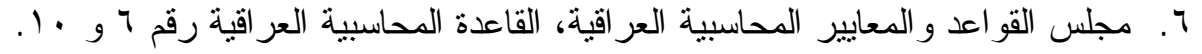

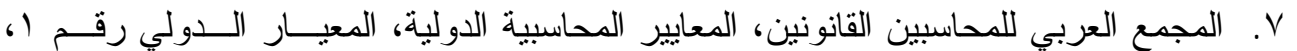
.1999

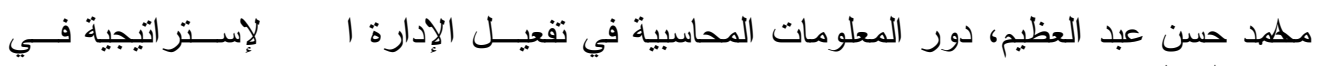

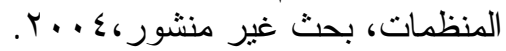

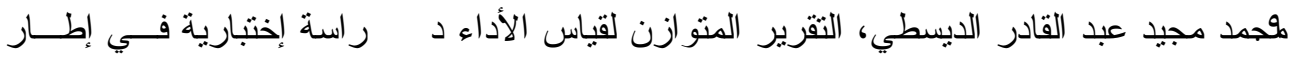

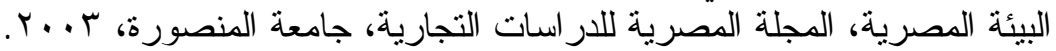

\section{ثانياً - المر اجع باللغة الإكليزية}

1. Boquist J.A,T.M Todd, and A.V thkar, How do you Win the Capital Allocation Game Sloan Management Review, 1998.

2. Bromubich, M., the Case for Strategic Management Competitive Markets Accounting, Organization and society, 1990.

3. Grundy, T, Johnson, G and Seholes, Exploring Strategic Financial Management, Prentice-Hall, Europe, 1998.

4. http://www.ardo,org/Activities Details . asp? type.

5. Mintzberg,H,the Strategy Concept: Five Ps for Strategy, California Management Review, Vol. Fall,1987.

6. Roslen, R,and S.Hart and J.Ghosh,Strategic Management Accounting Refocusing the Agenda, Management Accounting, December, 1998.

7. Wheelen,T.L and J.D Hunger, Strategic Management and Business Policy, 2002.

8. Zafriskie, N, B. and A. B. Huell, Developing Strategic Thinking in Senior Management Long Range Planning, Vol, 11, 1991. 